\title{
Targeting Syndecan-1, a molecule implicated in the process of vasculogenic mimicry, enhances the therapeutic efficacy of the L19-IL2 immunocytokine in human melanoma xenografts
}

\author{
Paola Orecchia ${ }^{1,3}$, Romana Conte ${ }^{1}$, Enrica Balza ${ }^{2}$, Gabriella Pietra ${ }^{1,3}$, Maria Cristina \\ Mingari, $^{1,3}$ and Barbara Carnemolla ${ }^{1}$ \\ ${ }^{1}$ Laboratory of Immunology, IRCCS AOU San Martino-IST, Genoa, Italy \\ ${ }^{2}$ Laboratory of Cell Biology, IRCCS AOU San Martino-IST, Genoa, Italy \\ ${ }^{3}$ Department of Experimental Medicine, University of Genoa, Genoa, Italy \\ Correspondence to: Barbara Carnemolla, email: barbaracarnemolla@libero.it \\ Keywords: vasculogenic/vascular mimicry, angiogenesis, sCFv OC-46F2 anti Syndecan-1, melanoma combined therapy, immu- \\ nocytokine L19-IL2 \\ Received: June 16, 2015 \\ Accepted: September 23, 2015 \\ Published: October 09, 2015
}

This is an open-access article distributed under the terms of the Creative Commons Attribution License, which permits unrestricted use, distribution, and reproduction in any medium, provided the original author and source are credited.

\section{ABSTRACT}

Anti-angiogenic therapy of solid tumors has until now failed to produce the long lasting clinical benefits desired, possibly due to the complexity of the neoangiogenic process. Indeed, a prominent role is played by "vasculogenic" or "vascular" mimicry (VM), a phenomenon in which aggressive cancer cells form an alternative microvascular circulation, independently of endothelial cell angiogenesis. In this study we observed, in melanoma patient cell lines having vasculogenic/stem-cell like phenotype and in melanoma tumors, the Syndecan-1 co-expression with VM markers, such as CD144 and VEGFR-2. We show that melanoma cells lose their ability to form tubule-like structures in vitro after blocking Syndecan-1 activity by the specific human recombinant antibody, OC-46F2. Moreover, in a human melanoma xenograft model, the combined therapy using OC-46F2 and L19-IL2, an immunocytokine specific for the tumor angiogenic-associated B-fibronectin isoform(B-FN), led to a complete inhibition of tumor growth until day $\mathbf{9 0}$ from tumor implantation in $\mathbf{7 1 \%}$ of treated mice, with statistically significant differences compared to groups treated with $\mathrm{OC}-46 \mathrm{~F} 2$ or L19-IL2 as monotherapy. Furthermore, in the tumors recovered from mice treated with OC-46F2 either as monotherapy or in combination with L19-IL2, we observed a dramatic decrease of vascular density and loss of VM structures. These findings indicate for the first time a role of Syndecan-1 in melanoma VM and that targeting Syndecan-1, together with B-FN, could be promising in improving the treatment of metastatic melanoma.

\section{INTRODUCTION}

Building on the premise that blood vessels are essential for tumor growth and metastasis in all solid tumors, including melanoma, anti-angiogenic therapy was originally developed to "starve" primary and metastatic tumors by blocking blood vessel recruitment [1-6]. However, while anti-angiogenic drugs are effective at reducing angiogenesis, these therapies have not produced widespread or long lasting clinical benefits and have shown their limitations, due to many other mechanisms involved in tumor progression and regulated by the tumor microenvironment [3, 7-9].

Metastatic melanoma is one of the deadliest forms of cancer; progress in its treatment, however, is very limited [10-13]. Recently L19-IL2, an immunocytokine specific for the angiogenesis-associated B-fibronectin isoform able to selectively accumulate on tumor neovasculature, was investigated in a randomized phase II clinical trial in patients with metastatic melanoma in combination with dacarbazine or with L19-TNF $\alpha$. Thus far, L19-IL2 has yielded encouraging results [10, 14-18]. 
It is known that in many malignant tumors, including metastatic melanoma, other forms of blood supply in tumor tissues exist in addition to angiogenesis. One of these mechanisms is "vasculogenic" or "vascular" mimicry (VM), in which cells of a highly aggressive malignant tumor can form vascular-like channels without implicating endothelial cells, thereby providing nutrients for tumor growth $[19,20]$. An emerging premise is that, in the cure of solid tumors, the most effective therapies will entail targeting combinations of factors for drug delivery. Markers of VM may therefore be important targets for this purpose [7-9, 20].

Many adhesion and membrane proteins, including MMP1/2, VEGFR-1/2, HIF-1, Nodal, FAK, EpHA2 and VE-cadherin (CD144), seem to be crucial to VM formation in many types of solid tumors such as melanoma and glioma [20-24]. VE-cadherin, specifically expressed in endothelial cells, is also expressed in aggressive melanoma cells and its expression knockdown inhibits VM formation, thus making it a major candidate marker of VM [25]. Recent studies have also implicated some cancer stem cell (CSC) markers such as CD133, ALDH1 and CD44 in VM formation [20].

Syndecan-1 (CD138), one of the four members of the syndecan family, is a cell surface heparan (HS) and chondroitin sulphate (CS) proteoglycan. Syndecan-1 is expressed predominantly in epithelial cells [26], but it is also found in B lymphocytes at specific stages of differentiation [27]. More recently, it was shown to be expressed also in malignant melanoma cells [22]. Syndecan-1 expression correlates to increased metastatic potential in melanoma cells [28]. The structural features of the HS-chains are responsible for the interaction of Syndecan-1 with a number of soluble factors, including pro-angiogenic factors like Vascular Endothelial Growth Factor (VEGF) and Fibroblast Growth Factor-2 (FGF$2)$, cell-associated molecules and extracellular matrix (ECM) components [26, 29, 30]. Furthermore, elevated levels of VEGF and shed Syndecan-1 form matrixanchored complexes that together activate integrin and VEGF receptors on endothelial cells, thereby stimulating tumor angiogenesis [31]. A number of findings suggest that Syndecan-1 is involved in the stimulation of CSC or tumor initiating cells (TIC) and that this can affect disease relapse and resistance to therapy [30] (and refs therein).

We recently demonstrated that Syndecan- 1 is a potential therapeutic target in melanoma and ovarian carcinoma. In fact, preclinical experiments of therapy in subcutaneous graft models of melanoma and ovarian carcinoma showed that $\mathrm{scFv}$ OC-46F2, specific for the ectodomain of Syndecan-1, inhibited vascular maturation and tumor growth [22].

In this study we demonstrate by in vitro and in vivo experiments that OC-46F2 antibody was able to inhibit the vascular mimicry of melanoma cells and vascular structure formation of endothelial cells. These findings indicate, for the first time, that Syndecan-1 is implicated in the process of vascular mimicry in melanoma. We report that OC46F2, administered systemically in combination with L19IL2, leads to a complete inhibition of tumor growth until day 90 from tumor implantation in $71 \%$ of treated mice. Moreover, at day 124 in the L19-IL2/OC-46F2 group, the tumor free survival was $64 \%$ in contrast to $0 \%$ observed in the L19-IL2 treated group. These results suggest that the combined therapy could improve the therapeutic efficacy of both OC-46F2 and L19-IL2 administered as single agents.

\section{RESULTS}

\section{Characterization of human metastatic melanoma cells showing vasculogenic phenotype}

We tested melanoma cell lines SKMEL28, MV3 and melanoma cells isolated from ten patients, all positive for Syndecan-1, to form tubule-like structures on Matrigel. Moreover, the ability of all cell lines to induce tumor growth and lung metastasis when injected subcutaneously or in the tail vein of NOD SCID mice, respectively, was assessed. As summarized in Table 1, SKMEL28, MV3, MeTA and MeMO were able to form tubule-like structures on Matrigel, and six out of seven subcutaneously inoculated melanoma cells isolated from patients were able to induce tumor growth as SKMEL28 cell line. Moreover, SKMEL28 and the two cell lines MeTA and MePA were able to metastatize to the lung after i.v. injections, as already described for the metastatic cell line MV3 [32]. To detect the human metastatic nodules we stained lung sections with the anti human Ki67 antibody that specifically recognizes human cells in proliferation (Supplementary Figure S1 A). Furthermore, we analyzed the c-Kit (CD117) expression and, in accordance with the literature [33], we observed that melanoma cells with a strong metastatic potential, such as SKMEL28, MePA, MeTA and MV3, were negative for c-Kit expression, in contrast to MeMI that expressed c-Kit (Table 1, Supplementary Figure S1 B and S2) and was unable to form metastases. We analyzed all melanoma cell lines for their expression of melanoma stem cell markers CD133/1 and CD271 by cytofluorimetric analysis. While CD133/1 was expressed only on MeTA, the majority of melanoma cell lines with vasculogenic phenotype were positive with CD271 (Supplementary Figure S2). Moreover, all melanoma cell lines expressed as mRNA other markers of cancer stem cells, such as CD44, ALDH1 and Nodal (data not shown).

We previously reported in Orecchia et al. 2013, that VEGFR-2 co-localized with Syndecan-1 in human melanoma xenograft. To investigate the role of VEGFR-2 in the melanoma VM, we performed in vitro Matrigel 
Table 1: Human metastatic melanoma cells characteristics associated to VM.

\begin{tabular}{ccccc}
\hline Cell lines & $\begin{array}{c}\text { vasculogenic } \\
\text { phenotype }\end{array}$ & $\begin{array}{c}\text { human tumors } \\
\text { xenografts/ } \\
\text { NOD SCID mice }\end{array}$ & $\begin{array}{c}\text { lung metastasis/ } \\
\text { NOD SCID mice }\end{array}$ & $\begin{array}{c}\text { c-Kit } \\
\text { expression }\end{array}$ \\
\hline SKMEL28 & yes & yes & yes & no \\
MV3 & yes & nd & yes & no \\
MeTA & yes & yes & yes & no \\
MeMO & yes & no & nd & no \\
MeMI & no & yes & no & yes \\
MePA & no & yes & yes & no \\
MeOV & no & yes & nd & no \\
MeCoP & no & yes & nd & yes \\
MeFeR & no & yes & nd & yes \\
MeBO & no & nd & nd & yes \\
MeTU & no & nd & nd & yes \\
MeDeBo & no & nd & nd & yes \\
\hline AbDiations: nd, not & & &
\end{tabular}

Abbreviations: nd, not determined

A

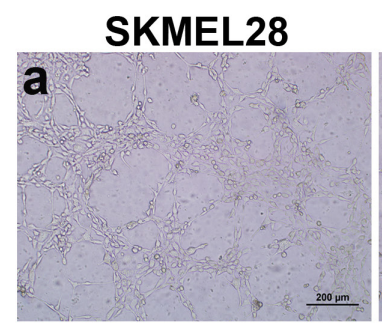

SU1498

DMSO
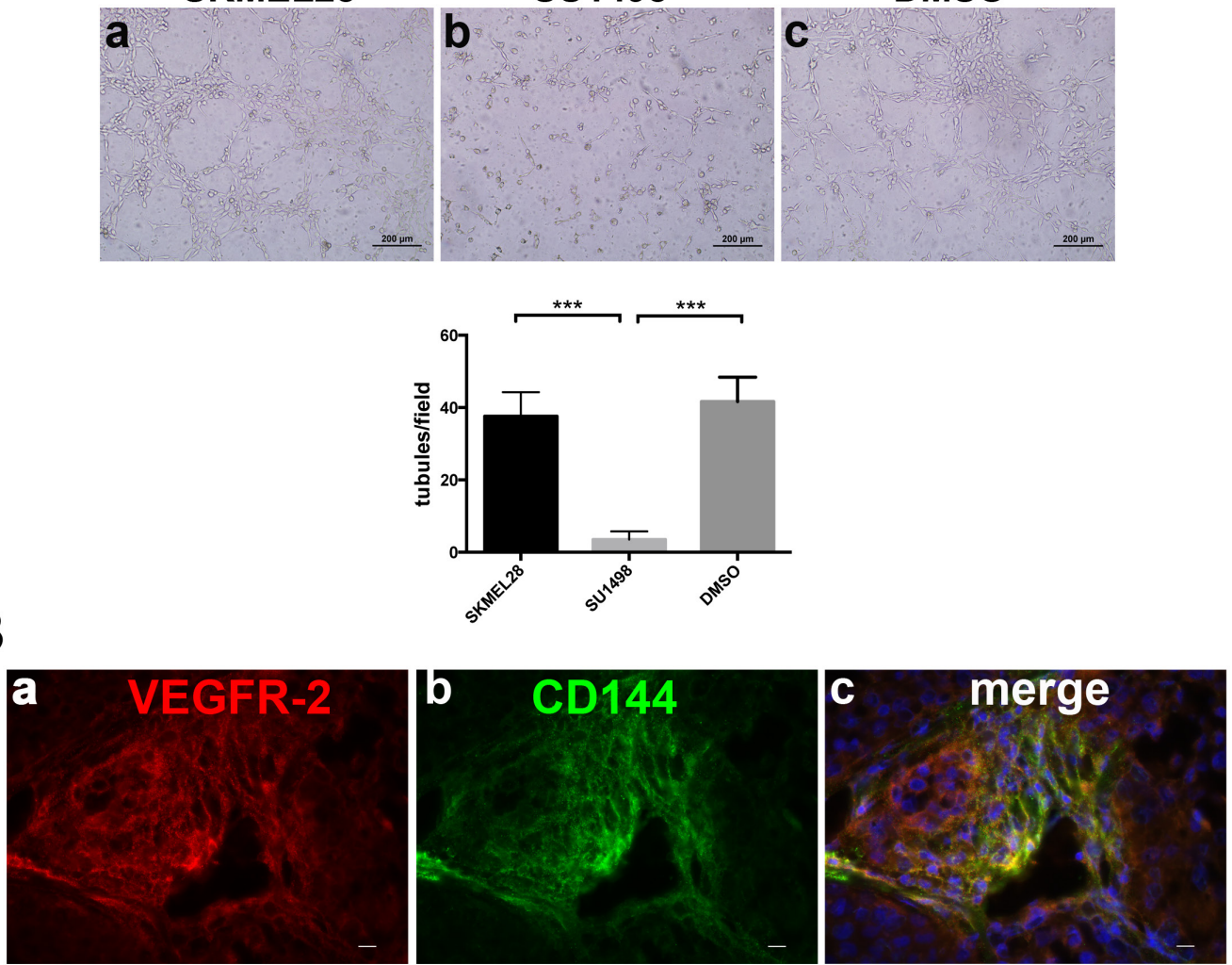

Figure 1: VEGFR-2 is involved in melanoma VM. A., In vitro Matrigel tube formation using melanoma cells SKMEL28 in presence of SU1498 (b) compared to untreated (a) or DMSO (c) treated cells. The differences in tubule formation were quantified by column bar graphs reported below the experiments. ${ }^{* * *}$ indicates extremely significant differences between treated and DMSO or untreated cells. Scale bars, $200 \mu \mathrm{m}$. The mean \pm SEM are indicated. B., representative immunofluorescence of cryostat sections of SKMEL28/NOD SCID, stained with anti VEGFR-2 (a) and anti CD144 (b). Merged image shows co-localization of VEGFR-2 with CD144 (c). Scale bars, $10 \mu \mathrm{m}$. 
experiments with or without SU1498, a specific VEGFR-2 kinase inhibitor using melanoma cells. As shown in Figure 1A, SU1498 inhibits the in vitro formation of tubule-like structures (b) compared to treated with DMSO (c) or not treated (a) cells. Moreover, by immunofluorescence staining on SKMEL28/NOD SCID sections, we show that VEGFR-2 (Figure 1B, a) co-localizes with CD144 (Figure $1 \mathrm{~B}, \mathrm{~b})$.

We chose three representative melanoma cells from patients (MeMI, MePA and MeTA) and SKMEL28 cell line and we observed that they were negative for the expression of human CD31, a marker of endothelial cells (Figure 2A and Supplementary Table S1), but that they expressed CD144 and VEGFR-2 (Figure 2B, 2C and Supplementary Table S1). These results indicate that tubular-like structures formed by melanoma tumor cells were not of endothelial origin. In Figure 2D, using
OC-46F2, we show representative micrographs in which Syndecan-1 (CD138) co-localized with CD144 (a-c; g-i) and VEGFR-2 (d-f; 1-n) in SKMEL28 and TIME cells.

In Figure 3A, by immunofluorescence staining on SKMEL28/NOD sections, we show that OC-46F2 was able to recognize vessels of human origin. In fact, the same vessels were positive with CD144 antibody specific for the human protein as indicated by arrowheads. Moreover, we show that Syndecan-1 co-localizes with VEGFR-2. The same results were observed with staining on MeTA/NOD SCID sections. In human metastatic melanoma biopsies obtained from different patients (Figure 3B) the same co-localization of Syndecan-1 with CD144 or VEGFR-2 was observed. All these results suggest that Syndecan-1 is present in the same tubular like structures expressing CD144 and VEGFR-2 markers of VM.

A
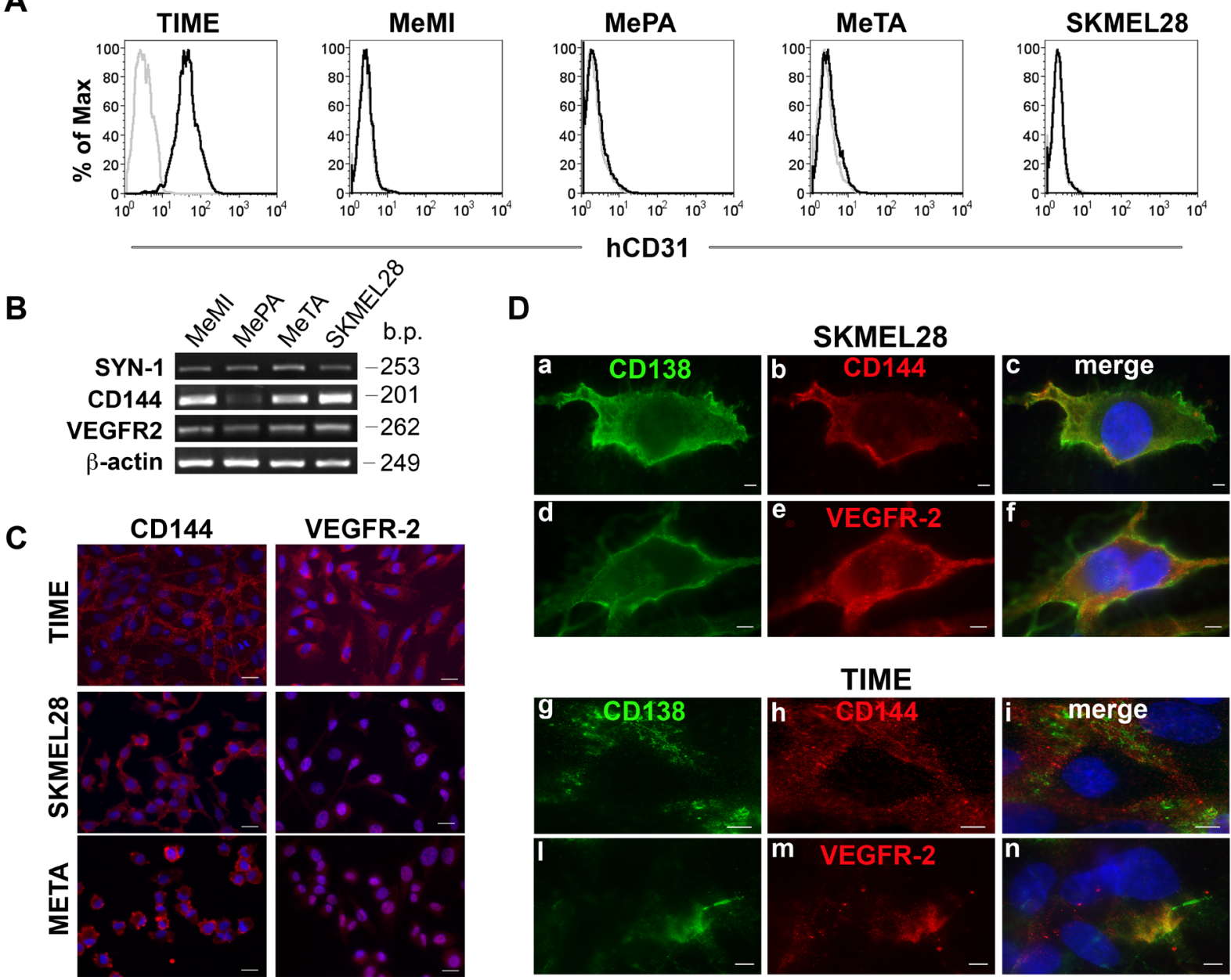

TIME
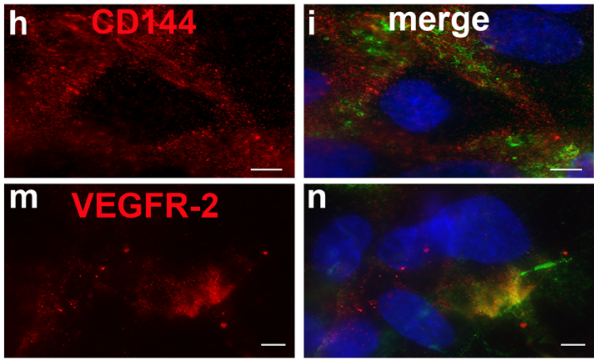

Figure 2: Expression of human CD31, CD144 and VEGFR-2 in positive Syndecan-1 melanoma cells. A., Flow cytofluorimetric analysis of human CD31 expression in TIME endothelial cell and MeMI, MePA, MeTA and SKMEL28 human melanoma cells. Gray profiles represent negative controls. B., RT-PCR analysis of human Syndecan-1, CD144 and VEGFR-2 expression in MeMI, MePA, MeTA and SKMEL28 human melanoma cells. Beta-actin was used as positive control. Base pairs (b.p.) of human genes are indicated. C., Immunofluorescence analysis of TIME endothelial cells, SKMEL28 and MeTA human melanoma cells stained with antiCD144 or anti VEGFR-2 counterstained with DAPI. Scale bars, $20 \mu \mathrm{m}$. D., Immunofluorescence analysis of SKMEL28 human melanoma cells and TIME endothelial cells in which co-distribution of syndecan-1 (CD138) with CD144 or VEGFR-2 is shown. The merged signals are shown in the right panel $(\mathrm{c}, \mathrm{f}, \mathrm{i}, \mathrm{n})$. Scale bars, $10 \mu \mathrm{m}$. 


\section{A}

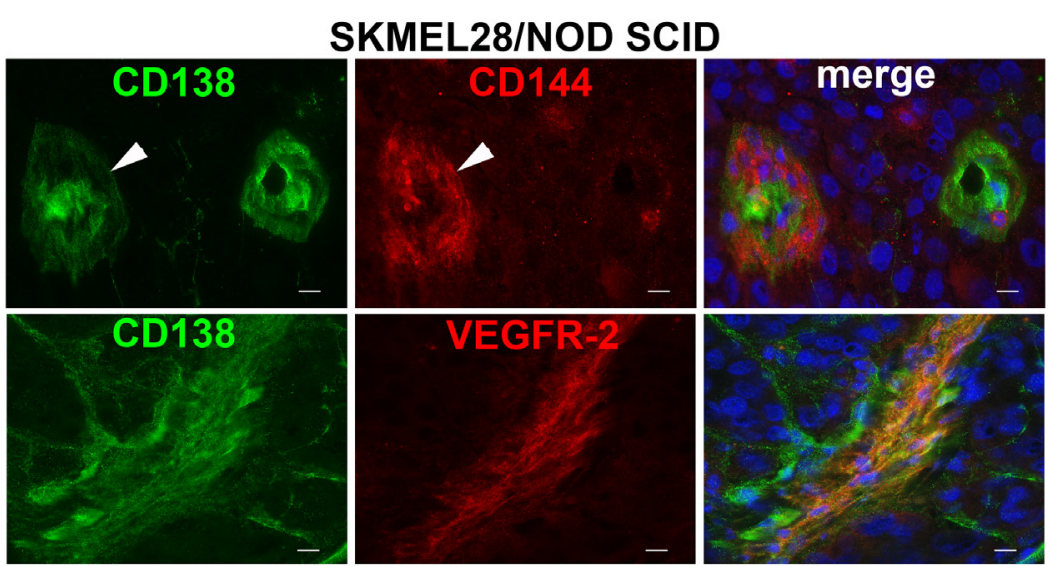

MeTA/NOD SCID
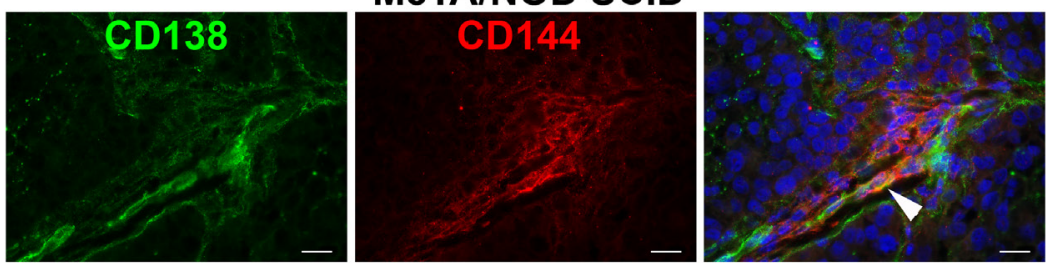

B

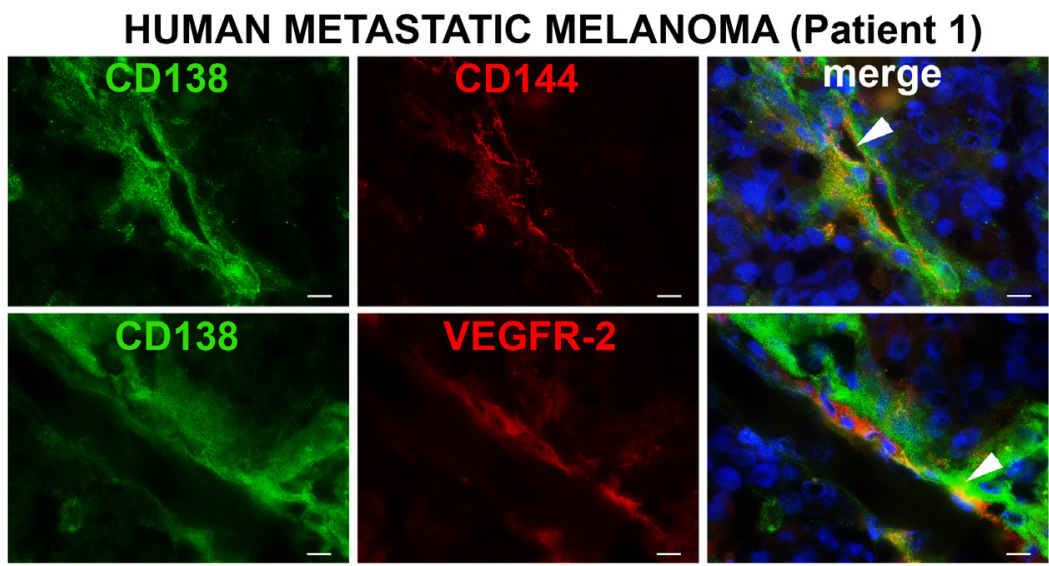

HUMAN METASTATIC MELANOMA (Patient 2)
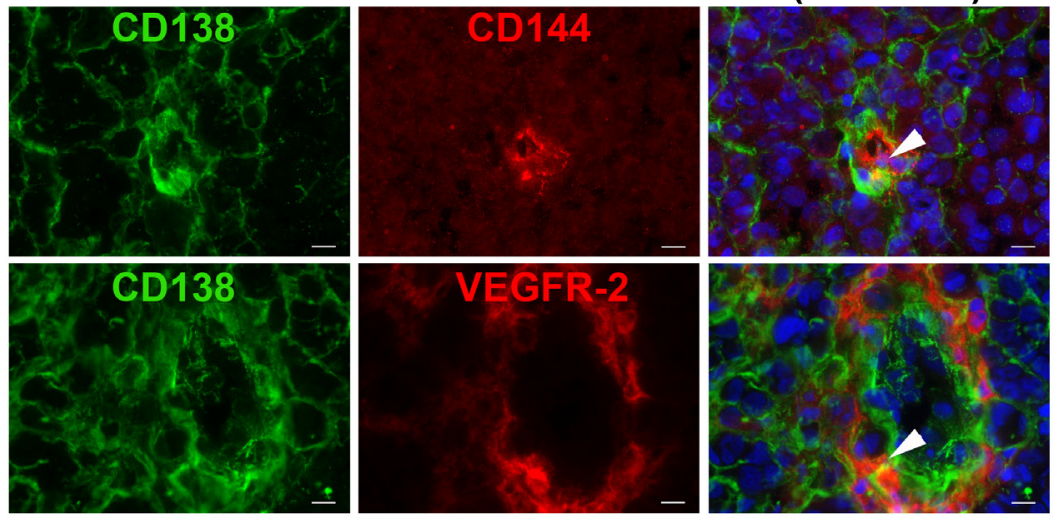

Figure 3: Syndecan 1 co-localizes with CD144 and VEGFR-2 in melanoma tissues. Immunofluorescence analysis of cryostat sections of SKMEL28 and MeTA melanoma tumors in NOD SCID mice A. and of human metastatic melanoma from two patients B. double stained with OC-46F2 and anti-VEGFR-2 or anti-CD144 antibodies as indicated in each picture and counterstained with DAPI. The merged signals are shown in the right panel. Scale bars, $10 \mu \mathrm{m}$. 


\section{A MeTA lung metastasis/NOD SCID mice}
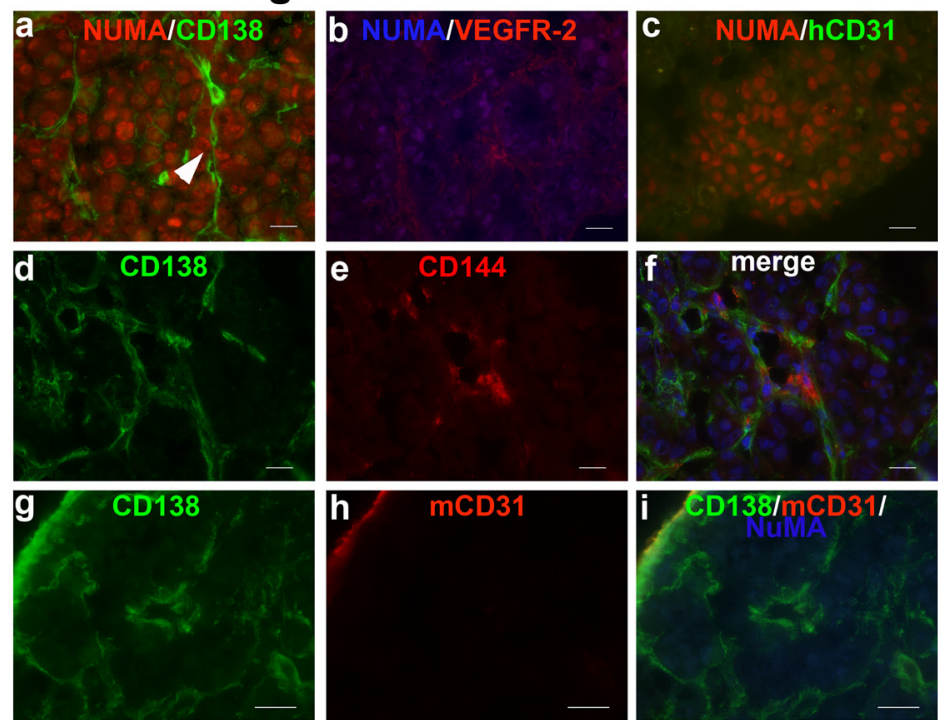

B

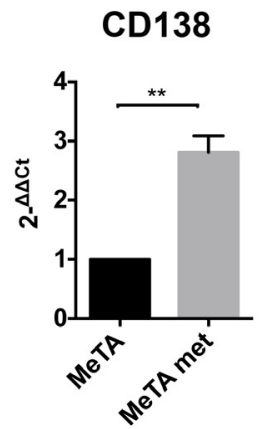

$$
\text { VEGFR-2 }
$$

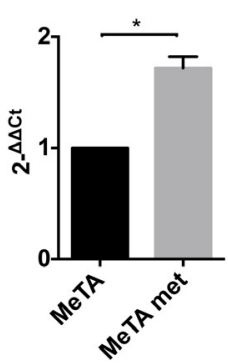

CD144

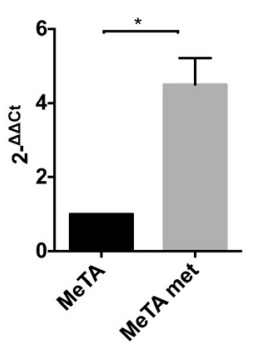

C

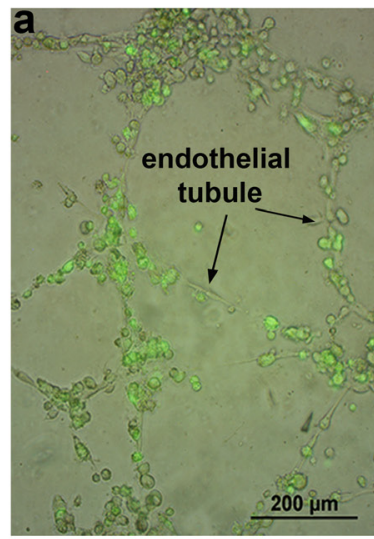

endothelial cell/MeTA-gfp

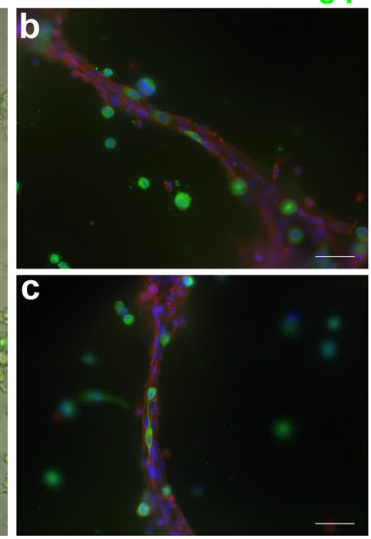

Figure 4: Expression of Syndecan-1 in lung metastases. A., Immunofluorescence of cryostat sections of lung metastasis induced by i.v. MeTA injection in NOD SCID mice double stained with anti-human NuMA and OC-46F2, anti-VEGFR-2, anti-hCD31, antihCD144 and anti mouse CD31 antibodies as indicated in each picture. Panel A (d-f) is counterstained with DAPI. Scale bars, $10 \mu \mathrm{m}$. B., qRT-PCR analysis of human Syndecan-1, VEGFR-2 and CD144 expression in human melanoma metastatic cells MeTA met in comparison to MeTA. 2- $[\Delta][\Delta]$ Ct is reported in the column bar graph. ${ }^{*}, * *$, indicate significant and very significant differences, between the two types of cells. C., Real time image of MeTA-GFP migration along endothelial tubules. Scale bars, $200 \mu \mathrm{m}$ (a). Fluorescent staining of tubular structures growth on Matrigel using anti-GFP antibody to localize melanoma cells and anti-human CD31 antibody specific for endothelial cells (b-c). Scale bars, $50 \mu \mathrm{m}$. 


\section{Human Syndecan-1, CD144 and VEGFR-2 expression in experimental lung metastasis of human melanoma}

To investigate the involvement of human Syndecan-1 in VM during the metastatic process, we performed immunofluorescence staining on lung sections of MeTA intravenously injected in NOD SCID mice. To specifically recognize all human melanoma cells, we used

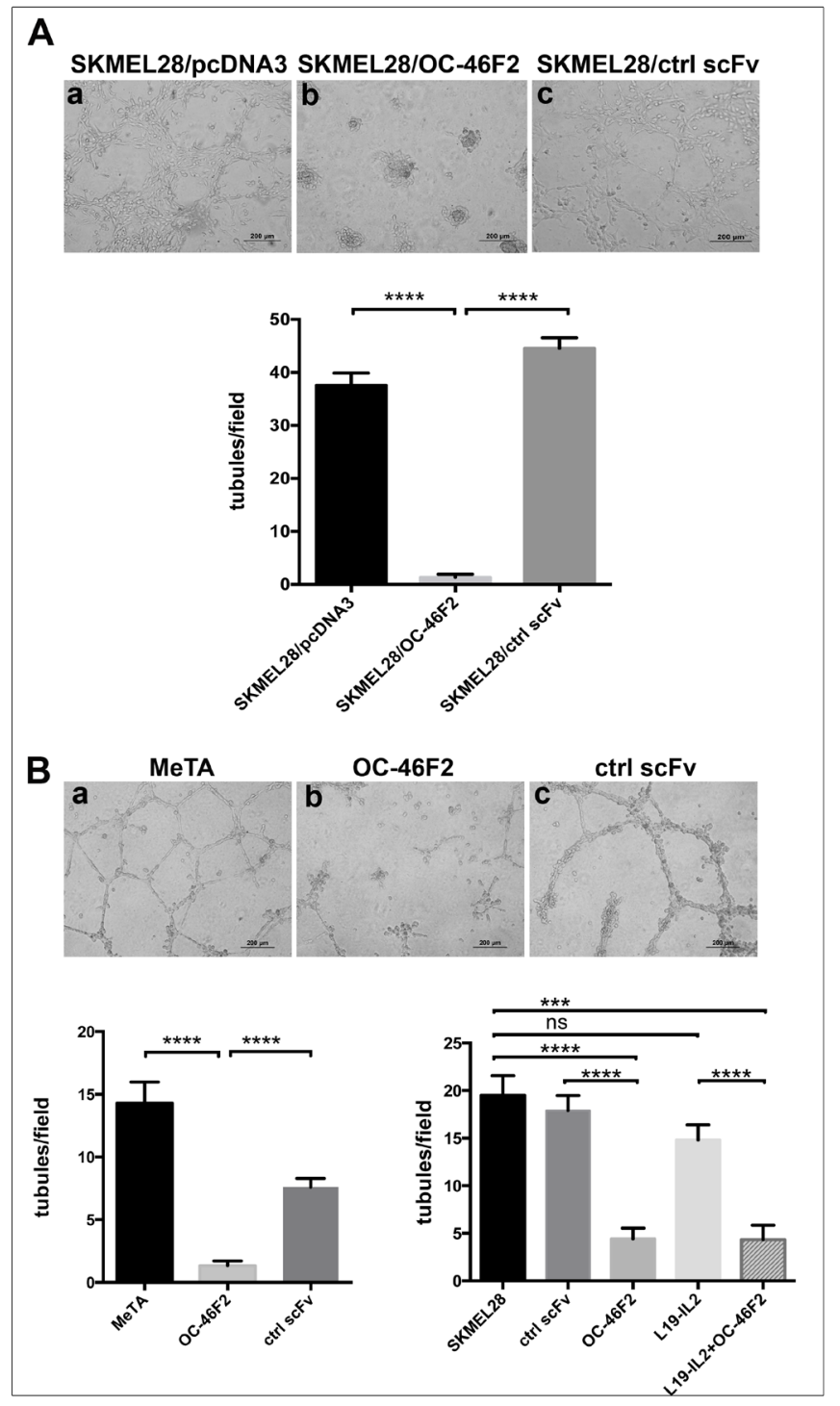

anti-human NuMA antibody and we observed a strong expression of Syndecan-1 (Figure 4A, a) and VEGFR-2 (Figure 4A, b) in NuMA positive melanoma cells. These data correlate with the qRT-PCR results, in which we observed a significant increase of Syndecan-1 mRNA expression in MeTA human melanoma cells isolated from murine lung metastases (MeTA met) compared to injected cells, as seen for VEGFR-2 and CD144 (Figure 4B). In Figure 4A we show, using OC-46F2 and anti human CD144 antibody (d-f), the presence of Syndecan-1

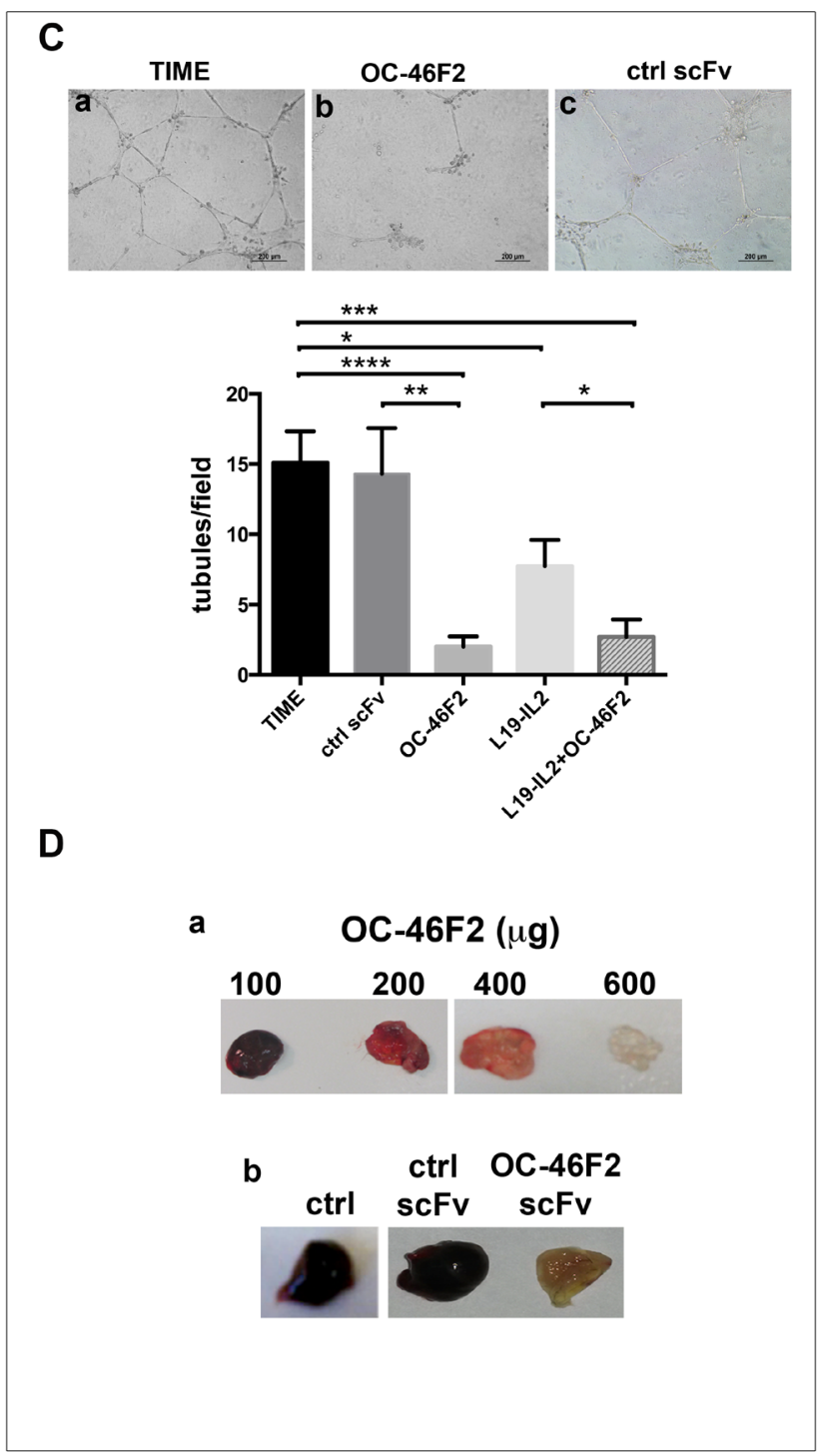

Figure 5: OC-46F2 inhibits vascular mimicry and angiogenesis. A., SKMEL28 stably transfected cells with OC-46F2 were not able to form tubule-like structures after 48 hours from plated cells on Matrigel (b) in comparison to cells transfected with the empty vector (a) or with a control scFv (c) that formed well organized structures. B., in vitro Matrigel tube formation using MeTA melanoma cells (a-c) or SKMEL28 in presence of OC-46F2 and/or L19-IL2 in comparison to control scFv treated or untreated cells. C., in vitro Matrigel vascular channel formation using TIME endothelial cells (a-c) in presence of OC-46F2 and/or L19-IL2 in comparison to control scFv treated or untreated cells. The differences in tubule formation at different treatments were quantified by column bar graphs reported below the corresponding experiments. Symbols indicate statistically differences between the groups connected by lines: ns, not significant; *, significant; **, very significant and ***, **** extremely significant. Scale bars, $200 \mu \mathrm{m}$. The mean \pm SEM are indicated. D., Photographs of plugs removed from OC-46F2 treated mice at different dose (a) and of representative plugs taken from untreated $(n=6)$, control scFv $(n$ $=6)$ or OC-46F2 treated mice $(n=6)(\mathrm{b})$. 
in tubule-like structures of human origin. All lung metastasis specimens were negative for human CD31 (c). Furthermore, the human tubule-like structures positive for OC-46F2 were negative for mouse CD31 (g-i). Figure 4C shows real time images of MeTA-GFP migration along endothelial tubules (a), and fluorescent staining, using anti-GFP and anti-human CD31 antibodies, illustrates the capacity of these tumor cells to localize along the external surface of vascular tubules, revealing a tropism for the vascular channels $(b, c)$.

\section{Anti Syndecan-1 human recombinant antibody, OC-46F2, inhibits vascular mimicry and angiogenesis in in vitro and in vivo Matrigel experiments}

To evaluate the capacity of OC-46F2 to inhibit vascular mimicry and angiogenesis, we performed in vitro experiments on Matrigel using SKMEL28, MeTA and TIME.

As shown in Figure 5A, SKMEL28 melanoma cells stably transfected with $\mathrm{scFv}$ OC-46F2 were not able to form tubule-like structures after 48 hours plated cells on Matrigel (b) in comparison to cells transfected with the empty vector (a) or with a control scFv (c) that formed well organized structures. A similar inhibitory effect of
OC-46F2 was obtained by adding the antibody at the concentration of $200 \mu \mathrm{g} / \mathrm{ml}$ to the cells. In fact, the in vitro formation of tubule-like structures by SKMEL28 and MeTA melanoma cells (Figure 5B) and of vascular structures by TIME endothelial cells (Figure 5C) was inhibited by scFv OC-46F2 (Figure 5B, b; 5C, b) compared to cells treated with control $\mathrm{scFv}$ (Figure $5 \mathrm{~B}, \mathrm{c}$; $5 \mathrm{C}$, c) or not treated (Figure 5B, a; 5C, a). No inhibition or a slight reduction of vascular channel formation was observed by adding L19-IL2 to SKMEL28 melanoma cell line (Figure 5B, right column bar graph) or TIME endothelial cells (Figure 5C), respectively. Moreover, we evaluated the anti-angiogenic effect of OC-46F2 using in vivo Matrigel plug assay. Indications of an anti-angiogenic effect in response to different doses of OC-46F2 can be assessed visually because of the color difference in the plugs (Figure 5D, a). As shown in Figure 5D, b, the representative plug removed from $\mathrm{OC}-46 \mathrm{~F} 2$ treated mice showed no FGF2-induced vascularization in contrast to plugs taken from control $\mathrm{scFv}$ treated or untreated mice.

These results suggest that Syndecan-1 is involved in the tubule-like formation of melanoma cells and vascular structure formation of endothelial cells. Furthermore, since OC-46F2 recognizes an epitope of the core protein of Syndecan-1, as demonstrated in Supplementary Figure S3 by treating human melanoma cells with PNPX, an elongation inhibitor of protein-associated

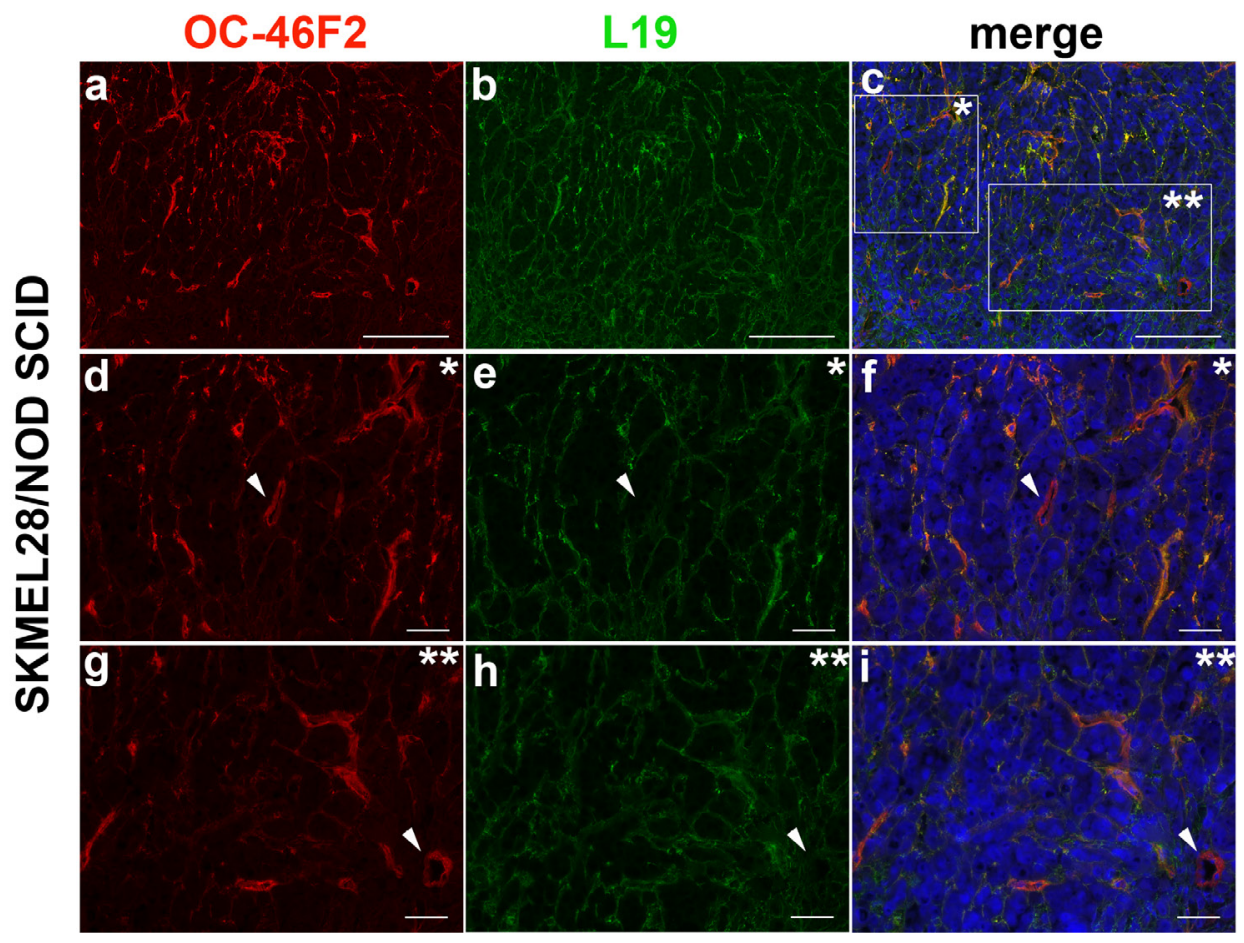

Figure 6: Immunofluorescence of cryostat sections of SKMEL28 melanoma tumors in NOD SCID mice double stained with OC-46F2 (a) and L19 (b) antibodies counterstained with DAPI. The merged signals show co-distribution of Syndecan-1 with B-fibronectin in some vascular structures (c); in * and ** magnifications, some vessels were positive with OC-46F2 only, as indicated by white arrowhead (d-f and g-i). Scale bars, $200 \mu \mathrm{m}$ (a-c) or $50 \mu \mathrm{m}(\mathrm{d}-\mathrm{i})$. 
glycosaminoglycan (GAG), it is conceivable that GAG chains of the molecule may not be implicated in these mechanisms.

\section{Therapeutic efficacy of $\mathrm{OC}-46 \mathrm{~F} 2$ in combination with L19-IL2 against human melanoma xenograft}

We recently reported that the human recombinant antibody, scFv OC-46F2, specific for the ectodomain of Syndecan-1, exerts an antitumor activity in vivo by reducing tumor growth and vascular maturation in experimental human melanoma and ovarian carcinoma murine models [22]. In line with our already published data $[15,22]$ we confirmed that $\mathrm{scFv}$ OC-46F2 and $\mathrm{L} 19$, an $\mathrm{scFv}$ specific for the angiogenesis-associated B-fibronectin isoform, stain both ECM and tumor vessels (Supplementary Figure S4). Interestingly, in this study we observed that the anti Syndecan-1 antibody, OC-46F2, stained some intratumoral vessels that were negative with L19 antibody. In fact, as shown in the representative Figure 6 (a-c) and in its magnifications (d-f, g-i), both OC-46F2 and L19 stain the majority of the vessels in the experimental human melanoma SKMEL28; however some vessels were positive with $\mathrm{OC}-46 \mathrm{~F} 2$ only (see arrowheads in Figure 6, d-f, g-i).

To investigate if a combined therapy with another drug, able to selectively localize to the tumor structures, could enhance the antitumor effect of scFv OC-46F2, we chose L19-IL2, an immunocytokine composed of human scFv L19 and IL2 [16, 34, 35].

Combination therapy experiments were performed in NOD SCID mice bearing SKMEL28 human melanoma. In a preliminary experiment, the doses used were $40 \mu \mathrm{g}$ for OC-46F2 and $40 \mu \mathrm{g}$ for L19-IL2 immunocytokine (given in combination) for each administration. The combination schedule of therapy is described in Materials and Methods and summarized in Figure 7A. As shown in Figure 7B until day 35 from melanoma cell subcutaneous implantation we observed a drastic reduction of tumor growth in $100 \%$ of mice compared to the untreated control group. From day 39, six out of thirteen mice (40\%) presented an increase of tumor volume; therefore a second cycle of combined therapy was administered following the combination schedule reported in Figure 7A. As shown in the upper right side of the Figure 7B, in all six treated mice the tumor volumes decreased from day 49 to day 56 when mice received OC-46F 2 only. The remaining seven out of thirteen mice $(60 \%)$ received no treatment. The two-tailed $p$ value of the two groups at day 46 and 49 from tumor implantation was very significant $(p$ value $=$ 0.0058 ) and significant ( $p$ value $=0,0192$ ), respectively. In this preliminary experiment the group of mice treated with the combined therapy shows a delay of 60 days of tumor growth respect to the control group that did not receive any therapy. A second experiment was carried out using a larger number of mice $(n=24)$ in order to have three groups that would receive a second cycle of therapy as follows: L19-IL2 and OC-46F2 as single therapy or in combination. Moreover, because OC-46F2 is completely non-toxic, we increased the dose of OC-46F2 to $80 \mu \mathrm{g}$ (high dose, HD), leaving the dose of L19-IL2 unchanged due to its toxicity. As shown in Figure 7C groups of mice were untreated or treated with OC-46F2, L19-IL2 as single therapy or combination therapy. The combination therapy (HD) completely inhibited tumor growth until day 90 in seventeen out of twenty four treated mice $(71 \%)$. From day 32 the two-tailed $p$ value of L19-IL2/OC-46F2 high dose group compared to OC-46F2 and L19-IL2 groups of mice was extremely significant $(p<0.0001)$ and very significant $(p=0.0037)$, respectively, indicating the strong efficacy of combined therapy (Figure 7C). In fact, at day 124 in the L19-IL2/OC-46F2 high dose group, the tumor free survival was $64 \%$ compared to $0 \%$ in L19-IL2 treated group (Figure 7D). To microscopically analyze tumor sections following combination treatments, the experiment was interrupted at day 140 when the tumor volumes were between 0.8 and $1.6 \mathrm{~cm}^{3}$. None of the groups exhibited a body weight loss greater than $3 \%$ at any time point during the treatments. The seven not completely responding mice out of twenty four $(29 \%)$ were randomized into three groups and subjected to a second cycle of therapy, as reported previously, following the treatment schedule described in Figure 7A for the mono- and combined therapy. A delay in tumor growth was observed in the group in which the two molecules were administered together (Supplementary Figure S5).

Figure 8A-C shows a drastic reduction of vessel numbers in tumors from mice that received $\mathrm{OC}-46 \mathrm{~F} 2$ either as monotherapy or combination therapy, as revealed using anti-Desmin and anti-SMA antibodies, markers of early and mature vessels, respectively. Moreover, the expression of the two VM markers, VEGFR-2 and CD144, was almost negative in the tumors from animals receiving OC-46F2 therapy (Figure $8 \mathrm{D}$ ). These in vivo experiments evaluating the change in vascular density and VM structures in the tumor tissues taken from treated mice confirm the efficacy of OC-46F2 in VM inhibition as above reported in in vitro results.

\section{DISCUSSION}

Poor five-year survival has been observed in some VM-forming aggressive cancers, including melanoma. Furthermore, a higher rate of VM has been reported in melanoma patients with metastasis compared to patients with primary melanoma, indicating that VM is able to promote tumor metastasis [20,36]. Recently accumulating research focuses on the availability of new anticancer treatments able to inhibit the formation of VM that could be combined with anti-angiogenic therapies. Thalidomide, one of the few anti-angiogenic agents that 
A

\begin{tabular}{|c|c|c|c|c|}
\hline \multicolumn{2}{|c|}{ MONOTHERAPY } & \multicolumn{3}{|c|}{ COMBINATION THERAPY } \\
\hline $\begin{array}{r}\text { OC-46F2 } \\
\text { 1st CYCLE } \\
\text { 2nd CYCLE }\end{array}$ & $\begin{array}{l}\text { OC-46F2 80ug } \\
\text { from } 8 \text { to } 25 \text { day, every day } \\
\text { from } 39 \text { to } 56 \text { day, every day }\end{array}$ & $\begin{array}{l}\text { L19-IL2/OC-46F2 LD } \\
\text { 1st CYCLE }\end{array}$ & $\begin{array}{c}\text { OC-46F2 } 40 \mu \mathrm{g} \\
\text { from } 8 \text { to } 25 \text { day, every day }\end{array}$ & 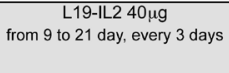 \\
\hline \multirow[t]{3}{*}{$\begin{array}{l}\text { L19-IL2 } \\
\text { 1st CYCLE } \\
\text { 2nd CYCLE }\end{array}$} & $\begin{array}{c}\text { L19-IL2 } 40 \mu \mathrm{g} \\
\text { from } 9 \text { to } 21 \text { day, every } 3 \text { days } \\
40,43,46 \text { day }\end{array}$ & $\begin{array}{l}\text { L19-IL2/OC-46F2 LD } \\
\text { 2nd CYCLE }\end{array}$ & $\begin{array}{c}\text { OC-46F2 } 40 \mu \mathrm{g} \\
\text { from } 39 \text { to } 56 \text { day, every day }\end{array}$ & $\begin{array}{l}\text { L19-IL2 40 } \mu \mathrm{g} \\
40,43,46 \text { day }\end{array}$ \\
\hline & & $\begin{array}{l}\text { L19-IL2/OC-46F2 HD } \\
\text { 1st CYCLE }\end{array}$ & $\begin{array}{c}\text { OC-46F2 } 80 \mu \mathrm{g} \\
\text { from } 8 \text { to } 25 \text { day, every day }\end{array}$ & $\begin{array}{c}\text { L19-IL2 } 40 \mu \mathrm{g} \\
\text { from } 9 \text { to } 21 \text { day, every } 3 \text { days }\end{array}$ \\
\hline & & $\begin{array}{l}\text { L19-IL2/OC-46F2 HD } \\
\text { 2nd CYCLE }\end{array}$ & $\begin{array}{c}\text { OC-46F2 } 80 \mu \mathrm{g} \\
\text { from } 46 \text { to } 63 \text { day, every day }\end{array}$ & $\begin{array}{l}\text { L19-IL2 40 } \mu \mathrm{g} \\
47,50,53 \text { day }\end{array}$ \\
\hline
\end{tabular}

B

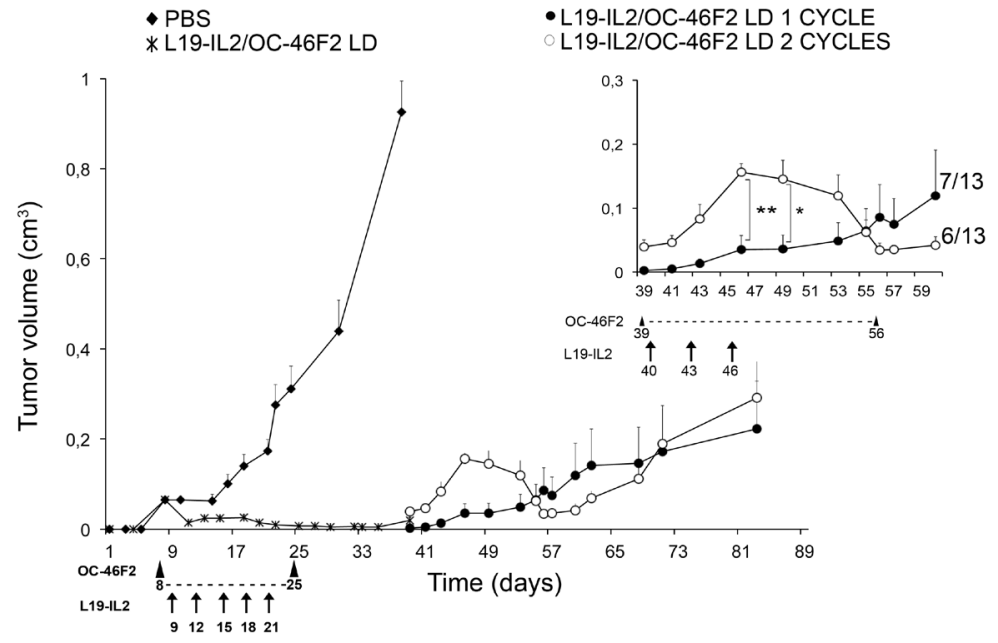

C

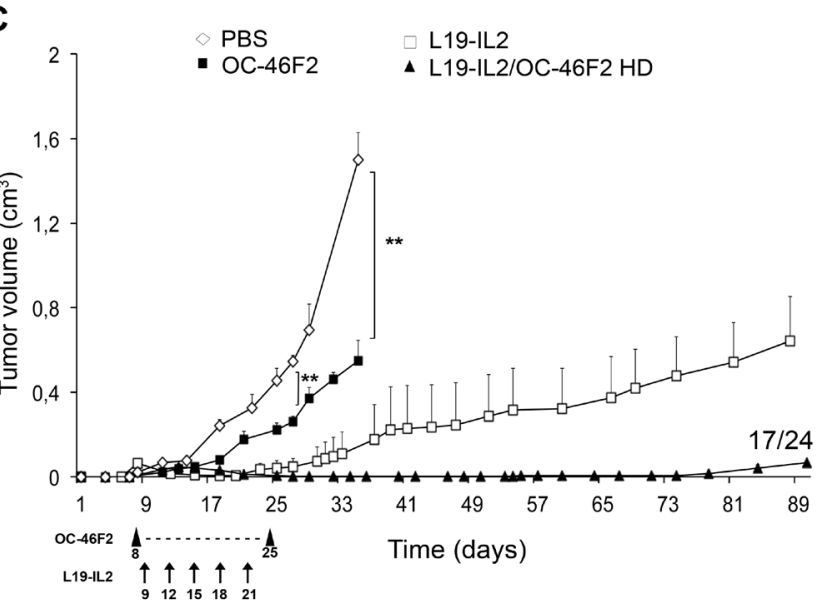

D

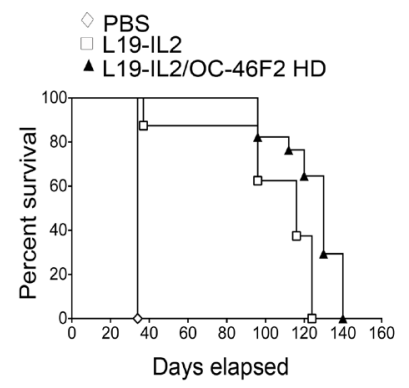

Figure 7: Targeting Syndecan-1 by scFv OC-46F2 enhances the therapeutic efficacy of immunocytokine L19-IL2 in melanoma. A., Administration schedule of OC-46F2 and L19-IL2 as single or combined treatments. Reported days are from tumor cells s.c. implantation. LD, Low Dose; HD, High Dose. Combination therapy experiments were started eight days after SKMEL28 human melanoma implantation in NOD SCID mice, when palpable tumors had developed. Mice were randomized in the different treatment groups. B., Tumor growth inhibition in mice $(\mathrm{n}=13)$ treated with L19-IL2 and OC-46F2 low dose administered in combination for eighteen days. In the upper right side a magnification of growth curve from day 39 is reported. Only $40 \%$ of mice $(n=6)$ were subjected to a second cycle of combination therapy of OC-46F2 every day for eight days and L19-IL2 on days $40,43,46$ as indicated by the arrows. * and ** indicate significant and very significant differences, respectively, between the group treated with second cycle and untreated group at days 46 and 49. C., Tumor growth inhibition in mice $(\mathrm{n}=24)$ treated with L19-IL2 and OC-46F2 at high dose administered as monotherapy or in combination. ** indicates very significant difference between the OC-46F2 treated and untreated groups at days 27 and 35 . From day 32 the two-tailed $\mathrm{p}$ value of L19-IL2/OC-46F2 high dose group of mice compared to OC-46F2 and L19-IL2 groups was extremely significant $(p$ $<0.0001, * * * *)$ and very significant $\left(p=0.0037,{ }^{* *}\right)$, respectively. The mean tumor volumes \pm SEM are indicated. Statistical significance of the differences between the groups was evaluated by nonparametric Mann Whitney test. D., Tumor free survival curves versus time (days) of SKMEL28 melanoma bearing mice treated with L19-IL2 as monotherapy, L19-IL2 and OC-46F2 HD as combination therapy or untreated. Arrowheads indicate the OC-46F2 treatment administrated every day in the reported range of days. Arrows indicate the L19-IL2 treatment administrated in the reported days. 
had shown efficacy in suppressing VM channels and mosaic vessel formation in an experimental model of melanoma, was never used in clinical applications due to its severe teratogenic effects [37]. Moreover, some anti-angiogenic agents, such as the monoclonal antibody bevacizumab, or endostatin and TNP-470, had no effect on VM; others, such as sunitinib, accelerate tumor cell VM in triple-negative breast cancer [23, 38-40]. The spectrum of therapeutic options for the cure of patients with advanced melanoma continues to expand, and a new anti-angiogenic drug, the immunocytokine L19-IL2, has been used in experimental phase II clinical trials for this deadly form of cancer [10, 14-18].

We recently reported that blocking Syndecan-1 activity via the human specific antibody scFv OC46F2 leads to an antitumor effect by inhibiting vascular maturation and tumor growth in experimental human melanoma and ovarian carcinoma models [22]. In this study we observed that VM of melanoma cells was inhibited by SU1498, a specific VEGFR-2 kinase inhibitor, as demonstrated in glioblastoma cell lines [23]. Our results are consistent with our previously reported
A

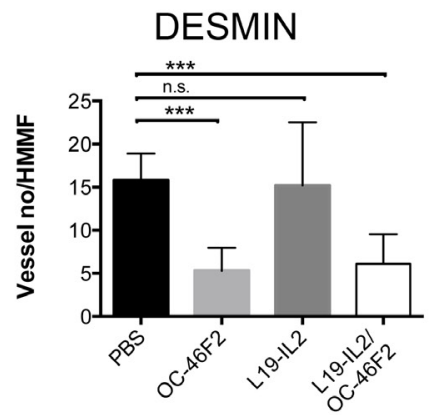

C

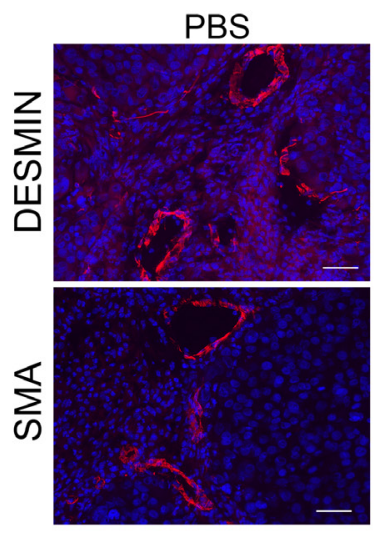

D

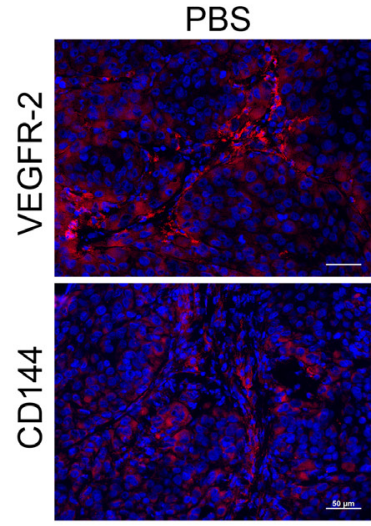

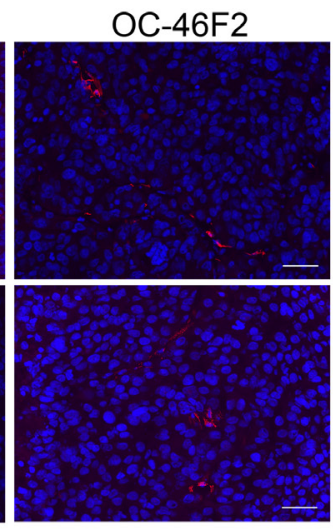
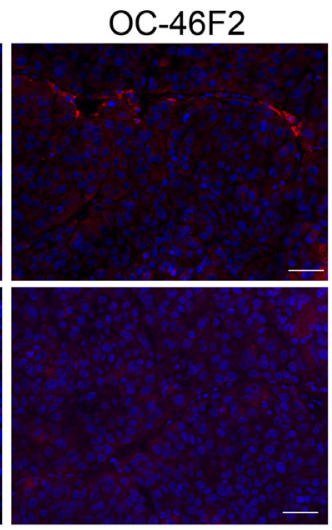

B
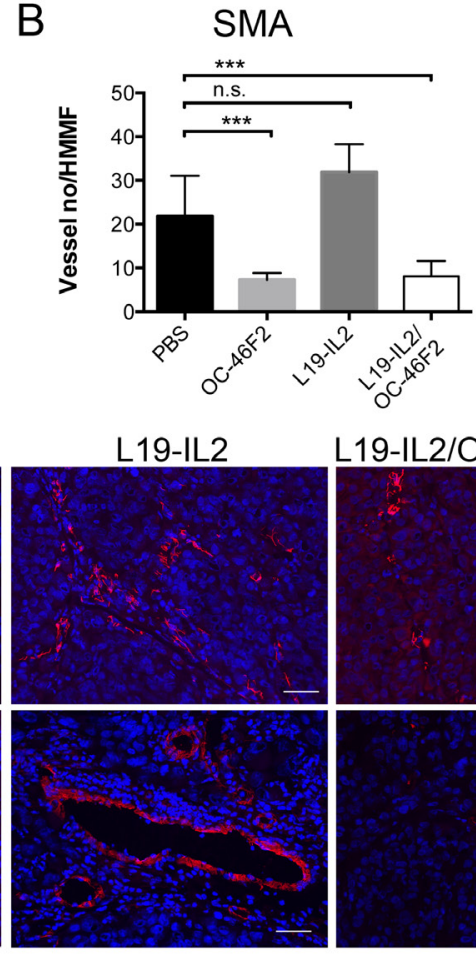

L19-IL2/OC-46F2 HD
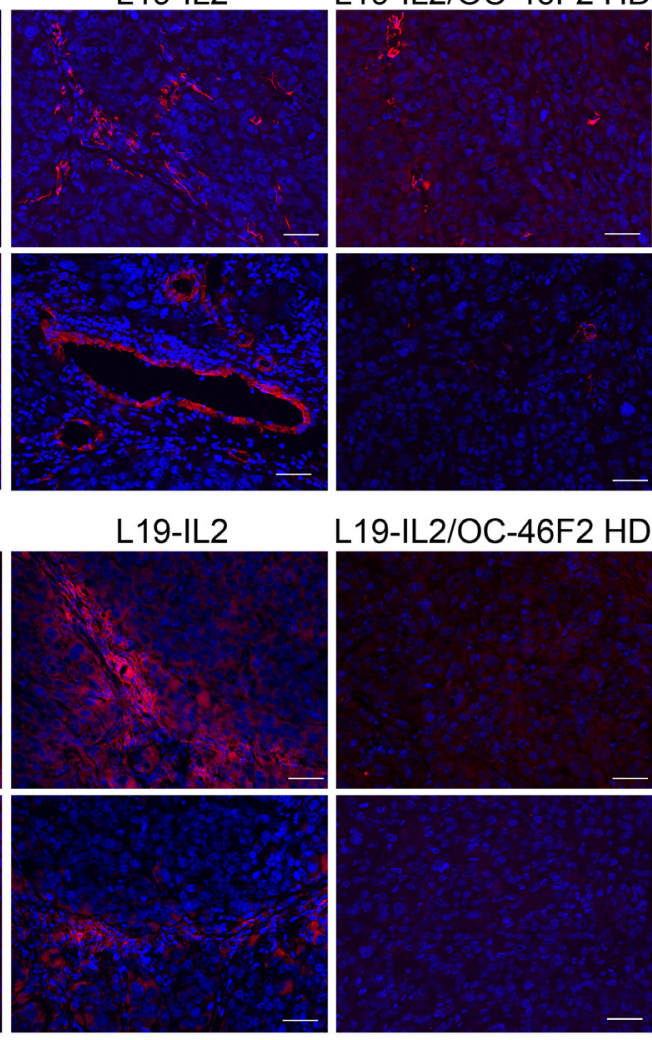

L19-IL2/OC-46F2 HD

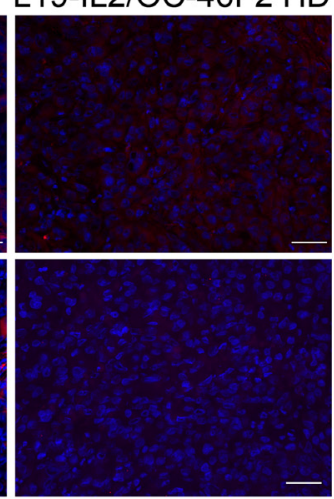

Figure 8: Therapeutic treatment with $\mathrm{OC}-46 \mathrm{~F} 2$ inhibits vascular maturation and induces loss of VM structures. Quantification of A. immature blood vessels (Desmin staining) and B. mature blood vessels (SMA staining) per HMMF in SKMEL-28 tumors subjected to different types of treatments. The mean \pm SEM are indicated. $* * *$ indicates extremely significant differences between OC-46F2 or L19-IL2/OC-46F2 HD treated and untreated groups. n.s. indicates not significant differences between L19-IL2 treated and untreated groups. Immunofluorescence analysis of cryostat sections of tumors recovered from SKMEL28/NOD SCID mice subjected to the different type of treatments stained with anti-desmin or anti-SMA C. and anti-VEGFR-2 or anti-CD144 D. antibodies as indicated in each picture and counterstained with DAPI. Scale bars, $50 \mu \mathrm{m}$. 
data and with many reports which describe an interaction between Syndecan-1 and VEGFR-2 [22, 23, 41, 42]. However, other VEGF receptors could be involved in VM, as recently reported for VEGFR-1 [24]. We demonstrated that Syndecan-1 positive melanoma cell lines having a vasculogenic and a stem cell-like phenotype, express two molecules involved in melanoma VM, such as CD144 and VEGFR-2 [20, 43]. Moreover, all these cell lines are negative with anti-CD31, differently from Dunleavey et al., who described a subpopulation of melanoma cells positive for CD31 but negative for VEGFR-2 [44]. We observed an increased Syndecan-1 mRNA expression in human melanoma cells isolated from murine lung metastases (MeTA met) compared to the injected cells (MeTA). Analyzing lung metastatic tissues we have shown that Syndecan-1 is expressed in the early stage of metastatic development, similarly to VEGFR-2 and CD144. Furthermore, the in vitro and in vivo experiments have shown that the antibody $\mathrm{OC}-46 \mathrm{~F} 2$ was able to inhibit human melanoma VM and to block the pro-angiogenic activity of Syndecan-1.

In a comparative study of Syndecan-1 and angiogenesis-associated $\mathrm{B}$-fibronectin isoform expression in melanoma tissues, using OC-46F2 and L19 antibodies, respectively, we observed that some vessels were positive with the anti-Syndecan-1 antibody but negative with L19. These preliminary observations afforded the possibility to investigate the effectiveness of $\mathrm{OC}-46 \mathrm{~F} 2$ in combination with the L19-IL2 immunocytokine in preclinical therapeutic experiments. Furthermore, the use of a human melanoma cell line in immune-compromised NOD SCID mice allowed us to study the human or murine origin of tumor vessels and to verify the efficacy of the two treatments specific for different targets of tumor stroma.

We found that the combination therapy using the OC-46F2 anti Syndecan-1 blocking antibody and the immunocytokine L19-IL2 leads to a complete inhibition of tumor melanoma growth until day 90 from tumor implantation in $71 \%$ of treated mice. A second cycle of combined therapy in the not completely responding mice was efficacious to induce a further delay in tumor growth. Moreover, by monitoring mice for a longer time, we observed that at day 124 , the tumor free survival was $64 \%$ in the L19-IL2/OC-46F2 high dose group compared to $0 \%$ observed in L19-IL2 treated group. The analysis of tumor tissues taken from mice treated with OC-46F2 as monotherapy or combination therapy confirms that the anti Syndecan-1 antibody inhibits vascular maturation and induces loss of VM structures.

These results suggest that the combined therapy could improve the therapeutic efficacy of L19-IL2 and OC-46F2 administrated as monotherapy, and that OC$46 \mathrm{~F} 2$ may be administered at high dose without any toxic effect. On the basis of these results, it will be interesting to extend the preclinical experiments of combined therapy to a model of human melanoma cells generated from patients.

In conclusion, these findings indicate for the first time the involvement of Syndecan-1 in the process of VM in metastatic melanoma. Blocking Syndecan-1 activity by OC-46F2 antibody in combination therapy with L19-IL2 could result in potential novel therapeutic approaches for metastatic melanoma. Moreover, our data are in line with the observation that the most effective therapies should target different factors involved in the mechanisms responsible for tumor progression.

\section{MATERIALS AND METHODS}

\section{Cell lines and human tissues}

Cultures of primary human melanoma cells MeTA, MeMO, MeMI, MePA, MeOV, MeCoP, MeFeR, MeBO, MeTU, MeDeBo [45], human metastatic melanoma MV3 cell line from S. Ferrone (New York Medical College), human melanoma SKMEL28 (ATCC, Rockville, MD) were grown in RPMI 1640 supplemented with 10\% FBS and $2 \%$ L-glutamine. The telomerase-immortalized human microvascular endothelium cell line, TIME (ATCC), was grown in Endothelial Cell Basal Medium-2 (EBM-2) which is supplied as part of the Microvascular Endothelial Cell Growth Medium-2 bullet kit (EGM-2-MV) available from Lonza/Clonetics Corporation (Basel, Switzerland). All cell lines were grown at $37^{\circ} \mathrm{C}$ in a $5 \% \mathrm{CO}_{2}$ incubator. All cell lines were used within six months of resuscitation.

MeTA met were isolated from murine lung metastasis and cultured in RPMI 1640 supplemented with $10 \%$ FBS and $2 \%$ L-glutamine until $100 \%$ of cells were positive with the specific anti human Ki67 antibody and tested by immunofluorescence.

Human metastatic melanoma tissues used in immunofluorescence analyses were obtained in accordance with informed consent procedures approved by the internal Ethics Board of the National Cancer Institute (IRCCS S. Martino-IST, Italy).

\section{Flow cytofluorimetric analysis}

For indirect one-colour cytofluorimetric analysis, cells were stained with scFv OC-46F2 $(5 \mu \mathrm{g} / \mathrm{ml})$ mixed with mouse monoclonal antibody immunoglobulin IgG1 anti-Myc 9E10 $(2.5 \mu \mathrm{g} / \mathrm{ml})$ (ATCC, Rockville, MD) or the mouse IgG1 anti-human CD31 (M0823, DAKO, Glostrup, Denmark). PE conjugated isotype specific goat antimouse IgG1 (Life Technologies) was used as secondary antibody. Melanoma cell lines SKMEL28 and MV3 were incubated overnight in presence or absence of $5-10 \mu \mathrm{g} / \mathrm{ml}$ of p-Nitrophenyl-beta-D-xylopyranoside (PNPX) (Sigma) [46]. The day after the expression of Syndecan-1 was highlighted by cytofluorimetric analysis using OC-46F2 
or B-A38 (10-520-C100, Exbio, Czech Republic). AntiCD133/1 (AC133) pure, PE-conjugated anti-c-Kit/CD117 (AC126-PE), anti-p75 neurotrophin receptor (NTR)/ $\mathrm{CD} 271-\mathrm{PE} \mathrm{mAbs}$ and their isotype-matched controls were purchased from Miltenyi Biotec $\mathrm{GmbH}$ (Bergisch Gladbach, Germany). PE-conjugated goat anti-mouse IgG1 mAb was purchased from Southern Biotechnology Associated (Birmingham, AL, USA).

\section{RT-PCR and qRT-PCR}

Total RNA was extracted from human melanoma cells harvested using RNAeasy mini kit (Qiagen). RealMasterScript SuperMix Kit (5 Prime) was used to generate cDNA. Amplifications were performed for 30 cycles $\left(30 \mathrm{~s}\right.$ at $95^{\circ} \mathrm{C}, 30 \mathrm{~s}$ at $58^{\circ} \mathrm{C}, 30 \mathrm{sec}$ at $\left.72^{\circ} \mathrm{C}\right)$ for all genes except for Syndecan-1 and Nodal, performed for 35 cycles, and CD144, performed for 40 cycles using Platinum TAQ (Life Technology). PCR products were run on a $1.5 \%$ agarose gel and visualized by ethidium bromide staining. A SybrGreen-based kit (Invitrogen) was used for Real Time PCR. Primers specific for human genes are reported in Supplementary Table S2.

\section{Purification and characterization of human recombinant antibody $\mathrm{OC}-46 \mathrm{~F} 2$ and immunocytokine L19-IL2}

The scFv OC-46F2, the immunocytokine L19-IL2 and their controls were purified from the conditioned media of mammalian cells expressing proteins using affinity columns and characterized as previously described $[22,34]$. Particularly, the OC-46F2 scFv and its control were purified on a ProteinA/Sepharose column (GE Healthcare) according to the manufacturer's instructions. The immunocytokine L19-IL2 was purified on ED-B fibronectin domain [47] conjugated to Sepharose 4B (GE Healthcare). Proteins were dialyzed against phosphate buffer saline (PBS) overnight at $+4^{\circ} \mathrm{C}$ and sterile filtered using Millex-GP $0.22 \mu \mathrm{m}$ filter unit (Millipore). Subsequently, they were analyzed under reducing conditions by sodium dodecyl sulfate-polyacrylamide gel electrophoresis (SDS-PAGE) and in native conditions by fast-protein liquid chromatography on a Superdex 200 column (Supplementary Figure S6).

\section{In vitro tubules formation assay}

Glass coverslips in 24-well cell culture plates were pre-coated with reduced growth factor Matrigel at the concentration of $18 \mathrm{mg} / \mathrm{ml}$ (354263, Corning, Bedford, US) and incubated for 30 minutes at $37^{\circ} \mathrm{C}$. Melanoma cells and endothelial cells were transferred at the density of $4 \times 10^{4}$ or $9 \times 10^{4}$ cells per well in complete specific medium, respectively, incubated at $37^{\circ} \mathrm{C} 5 \% \mathrm{CO}_{2}$ and then were observed for their capacity to form tubule-like structures or vascular tubules.

To test the ability of scFv OC-46F2 to inhibit tubule formation by melanoma cell lines SKMEL28 transfected with empty vector pcDNA3.1 or scFv OC-46F2 or control $\mathrm{ScFv}_{\mathrm{V}}$ [22] were plated on Matrigel in complete specific medium and incubated at $37^{\circ} \mathrm{C} 5 \% \mathrm{CO}_{2}$ for 48 hours. Moreover, OC-46F2 or control scFv and L19-IL2 were added at the concentration of $200 \mu \mathrm{g} / \mathrm{ml}$ after four to six hours when SKMEL28, MeTA and TIME started to form tubules [19]. All experiments were performed in triplicate. After fixation in $2 \%$ paraformaldehyde in PBS, the tubules formed were counted on ten different high magnification microscopic fields per coverslip under light microscopy (Leica Microsystems, Wetzlar, Germany) at $100 \mathrm{X}$ or 50X magnification for melanoma and endothelial cells, respectively. Images were captured using a DM LB2 microscope camera (Leica).

\section{Endothelial cell and melanoma cell co-culture on matrigel}

Glass coverslips in 24-well cell culture plates were pre-coated with reduced growth factor Matrigel at the concentration of $18 \mathrm{mg} / \mathrm{ml}$ (354263) and incubated for 30 minutes at $37^{\circ} \mathrm{C}$. TIME were transferred at the density of $1 \times 10^{5}$ cells per well in complete specific medium and incubated overnight at $37^{\circ} \mathrm{C} 5 \% \mathrm{CO}_{2}$. The day after tubule formation, MeTA-GFP $\left(4 \times 10^{4}\right.$ cells/well) were added and real time images were analyzed with an inverted microscope. After four hours, we performed fixation in $2 \%$ paraformaldehyde in PBS and immunofluorescence analysis.

\section{In vivo matrigel plug assay for angiogenesis}

C57BL6/J male mice (Charles River Laboratories International,Wilmington, MA, USA) were subcutaneously injected with $500 \mu$ l of reduced growth factor Matrigel phenol red free (356231, Corning) at the concentration of $10 \mathrm{mg} / \mathrm{ml}$ supplemented with $300 \mathrm{ng} / \mathrm{ml}$ FGF2 and 30UI/ml Heparin in absence or presence of 100 , 200,400 or $600 \mu \mathrm{g} /$ mouse of scFv OC-46F2 or control $\mathrm{scFv}$. After four days the animals were killed and the plugs removed $[48,49]$.

\section{Immunofluorescence and immunohistochemistry}

For immunofluorescence staining, tumors or lungs were excised, embedded in cryo embedding medium (Kaltek, Italy) and stored at $-80^{\circ} \mathrm{C}$. Cryostat sections $(6 \mu \mathrm{m})$ of tumors were fixed in ice-cold acetone for 10 minutes and dried at room temperature. Cells were plated 
on glass coverslips in a 24 -well cell culture plate in complete medium and were grown at $37^{\circ} \mathrm{C}$ in a $5 \% \mathrm{CO}_{2}$ incubator. Cells were fixed in $2 \%$ paraformaldehyde in PBS for 30 minutes and permeabilized in $0,1 \%$ Triton in PBS for 10 minutes.

For immunofluorescence we used scFv OC-46F2 (at the concentration of $5 \mu \mathrm{g} / \mathrm{ml}$ ) mixed with anti-Myc (at the concentration of $1.25 \mu \mathrm{g} / \mathrm{ml}$ ), the rat anti-mouse CD31 (clone MEC 13.3, kindly provided by A. Mantovani, Humanitas Institute, Milan, Italy), the mouse IgG1 antihuman CD31, the rabbit polyclonal anti-VEGF receptor-2 (ab2349, Abcam, UK), the mouse IgG2b anti humanCD144 (MAB9381, R\&D Systems, Minneapolis, USA), the human L19IgG1 anti B-fibronectin [15], the goat anti human NUMA (sc-18557, Santa Cruz, Texas, USA), the chicken polyclonal anti-GFP (ab13970, Abcam), the mouse anti human ki-67 (M0722, Sigma-Aldrich), the mouse anti-human smooth muscle actin (SMA) (DAKO) and the rabbit polyclonal anti-desmin (Abcam). As secondary antibody we used the Alexa Fluor 350, 488 or 594 goat anti-mouse $\mathrm{IgG}_{1}$ for anti-Myc and anti-human CD31, the Alexa Fluor 594 goat anti-rat for anti-mouse CD31, the Alexa Fluor 594 goat anti rabbit for anti-VEGF receptor-2, the Alexa Fluor 594 goat anti-mouse $\mathrm{IgG}_{2 \mathrm{~b}}$ for anti human-CD144, the Alexa Fluor 594 chicken anti goat or the Alexa Fluor 350 donkey anti goat for anti-Numa, the Alexa Fluor 488 goat anti chicken for anti-GFP and the Alexa Fluor 488 or 594 goat for L19IgG1, the Alexa Fluor 594 goat anti-mouse $\operatorname{IgG}_{2 \mathrm{a}}$ for anti-SMA and the Alexa Fluor 594 goat anti rabbit for anti-desmin (Life Technologies, USA). The tissue sections or cells were counterstained with DAPI using ProLong ${ }^{\circledR}$ Gold Antifade Mountant (Life Technologies) or Glycer gel (DAKO). Images were captured using a ApoTome microscope with AxioCam (Karl Zeiss, Thornwood, NY, USA). The immunohistochemical procedures have been described in Orecchia et al. [22].

\section{Animal experimental models}

Six-week-old female NOD SCID mice were originally obtained from the Charles River Laboratories International (Wilmington, MA, USA) and were bred in-house. Housing, treatment and sacrifice of animals followed national legislative provisions (Italian law no. 116,1992 and no. 26, 2014) for the protection of animals used for scientific purposes.

Six-week-old female NOD SCID mice were subcutaneously (s.c.) injected with $5 \times 10^{6}$ SKMEL28, MeTA, MeMO, MeMI, MePA, MeOV, MeCoP and MeFeR melanoma cells and the tumor growth was monitored daily. Specimens of SKMEL28 and MeTA human melanoma were obtained by subcutaneous injection of $10^{7}$ cells/mouse in NOD SCID mice. Animals were sacrificed when tumors reached a volume of about $1.0 \mathrm{~cm}^{3}$.
Six-week-old female NOD SCID mice were injected intravenously (i.v.) with the human melanoma MV3, SKMEL28, MeTA, MeMI, MePA cell lines $\left(1.5 \times 10^{6}\right.$ cells/ mouse). Eighteen days following the i.v. injection of MV3 cells and 45 days following the i.v. injection of other cell lines, mice were sacrificed and lungs were harvested.

In vivo treatments with purified OC-46F2 or immunocytokine L19-IL2 as monotherapy or combination therapy were performed in NOD SCID mice each s.c. injected with $10^{7}$ SKMEL28 human melanoma cells. When tumors were palpable, mice were randomized in the different treatment groups. In vivo treatments with purified OC-46F2 [22] or immunocytokine L19-IL2 [34] as monotherapy or combination therapy were performed in NOD SCID mice each s.c. injected with $10^{7}$ SKMEL28 human melanoma cells. When tumors were palpable different types of therapy were started.

For monotherapy, two groups of eight mice each received $80 \mu \mathrm{g} \mathrm{scFv}$ OC-46F2 every day from day eight to day twenty five by s.c. injection into the tail vein of each animal and $40 \mu \mathrm{g}$ L19-IL2 every three days from day nine to day twenty one by s.c. injection into the tail vein of each animal, respectively. Similar groups of animals were untreated. For the first cycle of combined therapy with low dose (LD) or high dose (HD) OC-46F2, two groups of thirteen or twenty four mice were injected with $40 \mu \mathrm{g}$ or $80 \mu \mathrm{g}$ of OC-46F2, respectively, together $40 \mu \mathrm{g}$ L19-IL2 following the same scheme of monotherapy. For the second cycle of combined therapy six mice of the LD group and three mice of the HD group were injected with $40 \mu \mathrm{g}$ or $80 \mu \mathrm{g}$ of OC-46F2, respectively, every day from day thirty-nine to day fifty-six day by s.c. injection, together $40 \mu \mathrm{g}$ L19-IL2 on days forty, forty-three and forty-six into the tail vein of each animal. For the second cycle of monotherapy in the HD group we followed the same scheme for combined therapy using OC-46F2 and L19-IL2 separately. On days in which both molecules were administered, OC-46F2 was injected into the peritoneum after six hours from L19-IL2 injection into the tail vein.

Every day from tumor cell implantation, the tumor volumes were determined using the following formula: $(d)^{2} \times D \times 0.52$, where $\mathrm{d}$ and $\mathrm{D}$ are the short and long dimensions (centimeters) of the tumor, respectively, measured with a caliper. The animals' weight was recorded daily. Animals were sacrificed when the tumor volume reached a volume between 0.8 and $1.6 \mathrm{~cm}^{3}$ and tumors were stored at $-80^{\circ} \mathrm{C}$.

\section{Statistical analysis}

All results are presented as mean \pm SEM. Statistically significance of the differences between the groups was evaluated by nonparametric Mann Whitney test using Prism 6 for MAC. 


\section{ACKNOWLEDGMENTS}

We gratefully acknowledge Prof. Dario Neri (ETH, Zurich, Switzerland) for critical reading of the manuscript, and Dr. Marina Gualco and Dr. Paola Queirolo (IRCCS San Martino-IST, Genoa, Italy) for providing metastatic melanoma biopsies. The authors thank Mr. Thomas Wiley for manuscript revision and Dr. Emanuela Ognio (IRCCS San Martino-IST, Genoa, Italy) for breeding the NOD SCID mice colony and for her help in mice handling.

\section{CONFLICTS OF INTEREST}

The authors have no conflicts of interest

\section{GRANT SUPPORT}

This work was supported by grants awarded by Associazione Italiana Ricerca sul Cancro (AIRC): IG 2010 project n. 10225, IG 2014 project n. 15283, "Special Program Molecular Clinical Oncology 5x1000" project n. 9962 and Ministero della Salute, Grant 5x1000, 2011 (M.C.M.).

P.O. is recipient of a fellowship funded by Ministero dell'Istruzione, dell'Università e della Ricerca: MIURFIRB 2003 project RBLA039LSF-001.

The funders had no role in study design, data collection and analysis, decision to publish, or preparation of the manuscript.

\section{REFERENCES}

1. Carmeliet P and Jain RK. Molecular mechanisms and clinical applications of angiogenesis. Nature. 2011; 473:298-307.

2. Folkman J. Angiogenesis: an organizing principle for drug discovery? Nat Rev Drug Discov. 2007; 6:273-286.

3. Weis SM and Cheresh DA. Tumor angiogenesis: molecular pathways and therapeutic targets. Nat Med. 2011; 17:13591370.

4. Chung AS, Lee J and Ferrara N. Targeting the tumour vasculature: insights from physiological angiogenesis. Nat Rev Cancer. 2010; 10:505-514.

5. Corrie PG, Basu B and Zaki KA. Targeting angiogenesis in melanoma: prospects for the future. Ther Adv Med Oncol. 2010; 2:367-380.

6. Emmett MS, Dewing D and Pritchard-Jones RO. Angiogenesis and melanoma - from basic science to clinical trials. Am J Cancer Res. 2011; 1:852-868.

7. Abdollahi A and Folkman J. Evading tumor evasion: current concepts and perspectives of anti-angiogenic cancer therapy. Drug Resist Updat. 2010; 13:16-28.

8. Moserle L, Jimenez-Valerio $G$ and Casanovas $O$. Antiangiogenic therapies: going beyond their limits. Cancer
Discov. 2014; 4:31-41.

9. Helfrich I and Schadendorf D. Blood vessel maturation, vascular phenotype and angiogenic potential in malignant melanoma: one step forward for overcoming antiangiogenic drug resistance? Mol Oncol. 2011; 5:137-149.

10. Pretto F and Neri D. Pharmacotherapy of metastatic melanoma: emerging trends and opportunities for a cure. Pharmacol Ther. 2013; 139:405-411.

11. Robert C, Thomas L, Bondarenko I, O’Day S, Weber J, Garbe C, Lebbe C, Baurain JF, Testori A, Grob JJ, Davidson N, Richards J, Maio M, Hauschild A, Miller WH, Jr., Gascon P, et al. Ipilimumab plus dacarbazine for previously untreated metastatic melanoma. N Engl J Med. 2011; 364:2517-2526.

12. Chapman PB, Hauschild A, Robert C, Haanen JB, Ascierto P, Larkin J, Dummer R, Garbe C, Testori A, Maio M, Hogg D, Lorigan P, Lebbe C, Jouary T, Schadendorf D, Ribas A, et al. Improved survival with vemurafenib in melanoma with BRAF V600E mutation. N Engl J Med. 2011; 364:2507-2516.

13. Ferrucci PF, Minchella I, Mosconi M, Gandini S, Verrecchia F, Cocorocchio E, Passoni C, Pari C, Testori A, Coco $\mathrm{P}$ and Munzone E. Dacarbazine in combination with bevacizumab for the treatment of unresectable/metastatic melanoma: a phase II study. Melanoma research. 2015; 25:239-245.

14. Danielli R, Patuzzo R, Ruffini PA, Maurichi A, Giovannoni L, Elia G, Neri D and Santinami M. Armed antibodies for cancer treatment: a promising tool in a changing era. Cancer immunology, immunotherapy. 2015; 64:113-121.

15. Borsi L, Balza E, Bestagno M, Castellani P, Carnemolla B, Biro A, Leprini A, Sepulveda J, Burrone O, Neri D and Zardi L. Selective targeting of tumoral vasculature: comparison of different formats of an antibody (L19) to the ED-B domain of fibronectin. International journal of cancer. 2002; 102:75-85.

16. Eigentler TK, Weide B, de Braud F, Spitaleri G, Romanini A, Pflugfelder A, Gonzalez-Iglesias R, Tasciotti A, Giovannoni L, Schwager K, Lovato V, Kaspar M, Trachsel E, Menssen HD, Neri D and Garbe C. A dose-escalation and signal-generating study of the immunocytokine L19IL2 in combination with dacarbazine for the therapy of patients with metastatic melanoma. Clin Cancer Res. 2011; 17:7732-7742.

17. Weide B, Eigentler TK, Pflugfelder A, Zelba H, Martens A, Pawelec G, Giovannoni L, Ruffini PA, Elia G, Neri D, Gutzmer R, Becker JC and Garbe C. Intralesional treatment of stage III metastatic melanoma patients with L19-IL2 results in sustained clinical and systemic immunologic responses. Cancer Immunol Res. 2014; 2:668-678.

18. Danielli R, Patuzzo R, Di Giacomo AM, Gallino G, Maurichi A, Di Florio A, Cutaia O, Lazzeri A, Fazio C, Miracco C, Giovannoni L, Elia G, Neri D, Maio M and Santinami M. Intralesional administration of L19-IL2/L19TNF in stage III or stage IVM1 a melanoma patients: results 
of a phase II study. Cancer immunology, immunotherapy. 2015; 64:999-1009.

19. Maniotis AJ, Folberg R, Hess A, Seftor EA, Gardner LM, Pe'er J, Trent JM, Meltzer PS and Hendrix MJ. Vascular channel formation by human melanoma cells in vivo and in vitro: vasculogenic mimicry. Am J Pathol. 1999; 155:739752.

20. Qiao L, Liang N, Zhang J, Xie J, Liu F, Xu D, Yu X and Tian Y. Advanced research on vasculogenic mimicry in cancer. J Cell Mol Med. 2015; 19:315-326.

21. Yao X, Ping Y, Liu Y, Chen K, Yoshimura T, Liu M, Gong W, Chen C, Niu Q, Guo D, Zhang X, Wang JM and Bian X. Vascular endothelial growth factor receptor 2 (VEGFR-2) plays a key role in vasculogenic mimicry formation, neovascularization and tumor initiation by Glioma stem-like cells. Plos One. 2013; 8:e57188.

22. Orecchia P, Conte R, Balza E, Petretto A, Mauri P, Mingari MC and Carnemolla B. A novel human anti-Syndecan-1 antibody inhibits vascular maturation and tumour growth in melanoma. Eur J Cancer. 2013; 49:2022-2033.

23. Francescone R, Scully S, Bentley B, Yan W, Taylor SL, Oh D, Moral L and Shao R. Glioblastoma-derived tumor cells induce vasculogenic mimicry through Flk-1 protein activation. The Journal of biological chemistry. 2012; 287:24821-24831.

24. Frank NY, Schatton T, Kim S, Zhan Q, Wilson BJ, Ma J, Saab KR, Osherov V, Widlund HR, Gasser M, WaagaGasser AM, Kupper TS, Murphy GF and Frank MH. VEGFR-1 expressed by malignant melanoma-initiating cells is required for tumor growth. Cancer research. 2011; 71:1474-1485.

25. Hendrix MJ, Seftor EA, Meltzer PS, Gardner LM, Hess AR, Kirschmann DA, Schatteman GC and Seftor RE. Expression and functional significance of VE-cadherin in aggressive human melanoma cells: role in vasculogenic mimicry. Proc Natl Acad Sci U S A. 2001; 98:8018-8023.

26. Xian X, Gopal S and Couchman JR. Syndecans as receptors and organizers of the extracellular matrix. Cell Tissue Res. 2010; 339:31-46.

27. Sanderson RD, Lalor P and Bernfield M. B lymphocytes express and lose syndecan at specific stages of differentiation. Cell Regul. 1989; 1:27-35.

28. O’Connell MP, Fiori JL, Kershner EK, Frank BP, Indig FE, Taub DD, Hoek KS and Weeraratna AT. Heparan sulfate proteoglycan modulation of Wnt5A signal transduction in metastatic melanoma cells. The Journal of biological chemistry. 2009; 284:28704-28712.

29. Teng YH, Aquino RS and Park PW. Molecular functions of Syndecan-1 in disease. Matrix Biol. 2012; 31:3-16.

30. Gharbaran R. Advances in the molecular functions of Syndecan-1 (SDC1/CD138) in the pathogenesis of malignancies. Crit Rev Oncol Hematol. 2015; 94:1-17.

31. Purushothaman A, Uyama T, Kobayashi F, Yamada S, Sugahara K, Rapraeger AC and Sanderson RD. Heparanase- enhanced shedding of Syndecan-1 by myeloma cells promotes endothelial invasion and angiogenesis. Blood. 2010; 115:2449-2457.

32. Wang X, Katayama A, Wang Y, Yu L, Favoino E, Sakakura K, Favole A, Tsuchikawa T, Silver S, Watkins SC, Kageshita $\mathrm{T}$ and Ferrone S. Functional characterization of an scFv-Fc antibody that immunotherapeutically targets the common cancer cell surface proteoglycan CSPG4. Cancer research. 2011; 71:7410-7422.

33. Huang S, Luca M, Gutman M, McConkey DJ, Langley KE, Lyman SD and Bar-Eli M. Enforced c-KIT expression renders highly metastatic human melanoma cells susceptible to stem cell factor-induced apoptosis and inhibits their tumorigenic and metastatic potential. Oncogene. 1996; 13:2339-2347.

34. Carnemolla B, Borsi L, Balza E, Castellani P, Meazza R, Berndt A, Ferrini S, Kosmehl H, Neri D and Zardi L. Enhancement of the antitumor properties of interleukin- 2 by its targeted delivery to the tumor blood vessel extracellular matrix. Blood. 2002; 99:1659-1665.

35. Kaspar M, Zardi L and Neri D. Fibronectin as target for tumor therapy. International journal of cancer. 2006; 118:1331-1339.

36. Cao Z, Bao M, Miele L, Sarkar FH, Wang Z and Zhou Q. Tumour vasculogenic mimicry is associated with poor prognosis of human cancer patients: a systemic review and meta-analysis. Eur J Cancer. 2013; 49:3914-3923.

37. Zhang S, Li M, Gu Y, Liu Z, Xu S, Cui Y and Sun B. Thalidomide influences growth and vasculogenic mimicry channel formation in melanoma. J Exp Clin Cancer Res. 2008; 27:60.

38. Wang R, Chadalavada K, Wilshire J, Kowalik U, Hovinga KE, Geber A, Fligelman B, Leversha M, Brennan C and Tabar V. Glioblastoma stem-like cells give rise to tumour endothelium. Nature. 2010; 468:829-833.

39. Seftor RE, Hess AR, Seftor EA, Kirschmann DA, Hardy KM, Margaryan NV and Hendrix MJ. Tumor cell vasculogenic mimicry: from controversy to therapeutic promise. Am J Pathol. 2012; 181:1115-1125.

40. Zhang D, Sun B, Zhao X, Ma Y, Ji R, Gu Q, Dong X, Li J, Liu F, Jia X, Leng X, Zhang C, Sun R and Chi J. Twist 1 expression induced by sunitinib accelerates tumor cell vasculogenic mimicry by increasing the population of CD133+ cells in triple-negative breast cancer. Mol Cancer. 2014; 13:207.

41. Rapraeger AC, Ell BJ, Roy M, Li X, Morrison OR, Thomas GM and Beauvais DM. Vascular endothelial-cadherin stimulates Syndecan-1-coupled insulin-like growth factor-1 receptor and cross-talk between alphaVbeta3 integrin and vascular endothelial growth factor receptor 2 at the onset of endothelial cell dissemination during angiogenesis. The FEBS journal. 2013; 280:2194-2206.

42. Lamorte S, Ferrero S, Aschero S, Monitillo L, Bussolati B, Omede P, Ladetto M and Camussi G. Syndecan-1 promotes 
the angiogenic phenotype of multiple myeloma endothelial cells. Leukemia. 2012; 26:1081-1090.

43. Civenni G, Walter A, Kobert N, Mihic-Probst D, Zipser M, Belloni B, Seifert B, Moch H, Dummer R, van den Broek $\mathrm{M}$ and Sommer L. Human CD271-Positive Melanoma Stem Cells Associated with Metastasis Establish Tumor Heterogeneity and Long-term Growth. Cancer research. 2011; 71:3098-3109.

44. Dunleavey JM, Xiao L, Thompson J, Kim MM, Shields JM, Shelton SE, Irvin DM, Brings VE, Ollila DW, Brekken RA, Dayton PA, Melero-Martin JM and Dudley AC. Vascular channels formed by subpopulations of PECAM1+ melanoma cells. Nat Commun. 2014; 5:5200.

45. Pietra G, Manzini C, Vitale M, Balsamo M, Ognio E, Boitano M, Queirolo P, Moretta L and Mingari MC. Natural killer cells kill human melanoma cells with characteristics of cancer stem cells. Int Immunol. 2009; 21:793-801.

46. Delcommenne $\mathrm{M}$ and Klingemann HG. Detection and characterization of Syndecan-1-associated heparan sulfate 6-O-sulfated motifs overexpressed in multiple myeloma cells using single chain antibody variable fragments. Hum Antibodies. 2012; 21:29-40.

47. Carnemolla B, Neri D, Castellani P, Leprini A, Neri G, Pini A, Winter G and Zardi L. Phage antibodies with panspecies recognition of the oncofoetal angiogenesis marker fibronectin ED-B domain. International journal of cancer. 1996; 68:397-405.

48. Passaniti A, Taylor RM, Pili R, Guo Y, Long PV, Haney JA, Pauly RR, Grant DS and Martin GR. A simple, quantitative method for assessing angiogenesis and antiangiogenic agents using reconstituted basement membrane, heparin, and fibroblast growth factor. Lab Invest. 1992; 67:519-528.

49. Prewett M, Huber J, Li Y, Santiago A, O’Connor W, King K, Overholser J, Hooper A, Pytowski B, Witte L, Bohlen $\mathrm{P}$ and Hicklin DJ. Antivascular endothelial growth factor receptor (fetal liver kinase 1) monoclonal antibody inhibits tumor angiogenesis and growth of several mouse and human tumors. Cancer research. 1999; 59:5209-5218. 